\title{
Construction of some new fractional canonical transformations and their generating functions
}

\author{
F. A. Abd El-Salam \\ ${ }^{1}$ Current Address: Taibah University, Faculty of Science, \\ Department of Mathematics, Al-Madeenah Al-Monawwarah, K.S.A \\ ${ }^{2}$ Permanent Address: Cairo University, Faculty of Science, \\ Department of Astronomy, Cairo, 12613, Egypt \\ f.a.abdelsalam@gmail.com
}

\begin{abstract}
The Fractional Calculus, in brief FC generalizes the differentiation and integration from integer to rational order. It enables us to derive equations of motion with non conservative classical forces using fractional Lagrangians. In this paper fundamental properties of fractional derivative are outlined. The behavior of some elementary functions under the effect of the fractional differintegral operator is examined. Using the Riemann-Liouville differintegral, Fractional Euler-Lagrange equation is obtained. Fractional Hamilton's canonical equations are formulated. Different canonical transformations with different generating functions are derived. Fractional Poisson bracket is introduced. Fractional Hamilton-Jacobi equation is presented.
\end{abstract}

Keywords: Riemann-Liouville derivative; Fractional Euler-Lagrange equation; Fractional Hamilton's canonical equations.

\section{Introduction}

The Fractional Calculus generalizes the ordinary differentiation and integration so as to include any arbitrary irrational order instead of being only the positive integers (Samko et al., 1993) Kilbas et al., 2006; Magin, 2006; Podlubny, 1999). In a letter to L'Hopital in 1695, Leibniz raised the possibility of generalizing the operation of differentiation to non-integer orders, and L. Hospital asked what would be the result of half-differentiating x. Leibniz replied, It leads to a paradox, from which one day useful consequences will be drawn. The paradoxical aspects are due to the fact that there are several different ways of generalizing the differentiation operator to non-integer powers, leading to inequivalent results. During the second half of the twentieth century, many authors have explored the world of FC giving new insight into many areas of scientific research in physics, mechanics and mathematics. Miller and Ross (1993) pointed out, there is hardly of science or engineering that has remained untouched by the new concepts of FC.

To move from the integer-order calculus to the $\mathrm{FC}$ version of a system we replace the time derivative in an evolution equation with a derivative of fractional order. Riewe (1996), (1997) has formulated Lagrangian and Hamiltonian mechanics to included derivatives fractional order. It has been shown that Lagrangianinvolving fractional time derivatives lead to equations of motion with non conservative classical forces such as friction using certain functional. In these references, fractional derivative terms were introduced in functional to obtain neoconservative terms in the desired differential equation. Agawal in a very interesting series of papers (Agrawal, 2002; 2006; 2007) has developed fractional calculus of variations dealing with Lagrangian involving Riemann-Louville (R-L) fractional derivatives. He has presented fractional Euler-Lagrange equations involving Caputo derivatives. Baleanu and Muslih (2005a; b) developed a fractional Hamiltonian in terms of Caputo derivatives. Baleanu (2008) compared the results of fractional Euler-Lagrange equations corresponding to several fractional generalized derivatives. He presented fractional Lagrangians which differ by a fractional Riesz derivative. He showed the difference of the obtained fractional Euler-Lagrange equations when several fractional derivatives are used, namely the Riemann- Liouville, Caputo and Riesz derivatives.

In fact Poisson brackets constitute important part of Hamiltonian mechanics. Entire Hamiltonian mechanics can be restated in terms of the fractional Poisson-brackets. In view of this a generalization of Poisson-bracket (fractional version) is suggested. Hamilton canonical equations (fractional case) havebeen expressed in terms of fractional Poisson bracket. A nil word is that with the fractional mechanics we can describe both conservative and non-conservative systems with only one equation of motion. 


\subsection{The fractional derivatives}

The ordinary derivative of a function $\mathrm{f}(\mathrm{x})$ is defined as

$$
\frac{d}{d x} f(x)=D_{x}^{1}[f(x)]=\lim _{h \rightarrow 0} \frac{f(x+h)-f(x)}{h}
$$

Iterating this operation yields an expression for the $\mathrm{n}^{\text {th }}$ derivative of a function denoted by $\frac{\mathrm{d}^{\mathrm{n}}}{\mathrm{dx}^{\mathrm{n}}}=\mathrm{D}_{\mathrm{x}}^{\mathrm{n}}$. As can be easily seen and proved by induction for any natural number $\mathrm{n}$

$$
D_{x}^{n}[f(x)]=\lim _{h \rightarrow 0} \frac{1}{h^{n}} \sum_{k=0}^{n}(-1)^{k}\left(\begin{array}{l}
n \\
k
\end{array}\right)[f(x+k h)]
$$

where, the binomial coefficient is given by the factorial function that is defined only for integer numbers as

$$
\left(\begin{array}{l}
\mathrm{n} \\
\mathrm{k}
\end{array}\right)=\frac{\mathrm{n} !}{\mathrm{k} !(\mathrm{n}-\mathrm{k}) !}
$$

Such an expression could be valuable for instance in a simple program for plotting the $\mathrm{n}^{\text {th }}$ derivative of a function. Viewing this expression one asks immediately if it can be generalized to any non-integer, real numbers $\mathbb{R}$ or even to complex number $\mathbb{C}$.

To generalize the ordinary operator so as to compute the fractional order differentiation, we need a function that is not singular for the fractional factorials. Fortunately it is exists a special function, the gamma function, that has the property of generalization of the factorial function over the real numbers except zero and the negative integers. The gamma function is defined as:

$$
\Gamma(\mathrm{z})=\int_{0}^{\infty} \mathrm{x}^{\mathrm{z}-1} \mathrm{e}^{-\mathrm{z}} \mathrm{dx}=(\mathrm{z}-1) \text { ! }
$$

That the generalization of the factorial by the gamma function allows:

$$
\left(\begin{array}{l}
\mathrm{n} \\
\mathrm{k}
\end{array}\right)=\frac{\mathrm{n} !}{\mathrm{k} !(\mathrm{n}-\mathrm{k}) !}=\frac{\Gamma(\mathrm{n}+1)}{\Gamma(\mathrm{k}+1) \Gamma(\mathrm{n}-\mathrm{k}+1)}
$$

which is valid for all real numbers except for the negative integers?

The likeness of to the binomial formula:

$$
(\mathrm{a}+\mathrm{b})^{\mathrm{n}}=\sum_{\mathrm{k}=0}^{\infty}\left(\begin{array}{l}
\mathrm{n} \\
\mathrm{k}
\end{array}\right)\left(\mathrm{a}^{\mathrm{n}-\mathrm{k}} \mathbf{b}^{\mathrm{k}}\right)
$$

which can be generalized to any real or complex number $\alpha$ by

$$
(\mathrm{a}+\mathrm{b})^{\alpha}=\sum_{\mathrm{k}=0}^{\infty}=\frac{\Gamma(\alpha+1)}{\Gamma(\mathrm{k}+1) \Gamma(\alpha-\mathrm{k}+1)}\left(\mathrm{a}^{\alpha-\mathrm{k}} \mathrm{b}^{\mathrm{k}}\right)
$$

which is convergent if $|\mathrm{b}|<\mathrm{a}$.

The integral (3) is defined for $z>0 \quad($ or $\operatorname{Re}(z)>0 \quad$ if $z \in \mathbb{C}$ ) and can be checked by elementary integration that for $z$ integer this function coincide with the factorial; more precisely it holds: $\Gamma(\mathrm{n}+1)=\mathrm{n}$ !. We are ready now to define a real-indexed derivative, or more generally, a complexindexed derivative $\mathrm{D}_{\mathrm{x}}^{\alpha}$ with $\alpha \in \mathbb{R}($ or $\alpha \in \mathbb{C})$, of a monomial $\mathrm{x}^{\beta}$ as

$$
\mathrm{D}_{\mathrm{x}}^{\alpha}\left[\mathrm{x}^{\beta}\right]=\frac{\Gamma(\beta+1)}{\Gamma(\beta+1-\alpha)} \mathrm{x}^{\beta-\alpha}, \mathrm{m}>\mathrm{n}
$$

Since Gamma function is not defined for zero and the negative integers, then $\beta+1 \neq 0,-1,-2,-\mathrm{n}$.

Now let us consider the case where the index of the monomial is negative integer valued: $\beta+1 \neq 0,-1,-2,-\mathrm{n}$. and we operate with the ordinary integer derivative.

Consider the monomial function $\mathrm{f}(\mathrm{x})=\mathrm{x}^{\mathrm{m}}$ with $\mathrm{m}$ a positive definite integer, from which we obtain,

$$
\begin{array}{rlr}
\mathrm{D}_{\mathrm{x}}^{\mathrm{n}}\left[\mathrm{x}^{-\mathrm{m}}\right] & =(-1)^{\mathrm{n}} \mathrm{m}(\mathrm{m}+1)(\mathrm{m}+2) \ldots .(\mathrm{m}+\mathrm{n}-1) \mathrm{x}^{-(\mathrm{m}+\mathrm{n})} \\
& =\frac{\mathrm{m} !}{(\mathrm{m}-\mathrm{n}) !} \mathrm{x}^{\mathrm{m}-\mathrm{n}}, \quad \mathrm{m}>\mathrm{n}
\end{array}
$$

or using the properties of gamma functions:

$$
\mathrm{D}_{\mathrm{x}}^{\mathrm{n}}\left[\mathrm{x}^{-\mathrm{m}}\right]=(-1)^{\mathrm{n}} \frac{\Gamma(\mathrm{m}+\mathrm{n})}{\Gamma(\mathrm{m})} \mathrm{x}^{-(\mathrm{m}+\mathrm{n})}, \quad \mathrm{n} \in \mathbb{N}
$$


If we restrict ourselves to real indices, then again proceeding by analogy we write for $0<\alpha<1$;

$$
\mathrm{D}_{\mathrm{x}}^{\alpha}\left[\mathrm{x}^{-\mathrm{m}}\right]=(-1)^{\alpha} \frac{\Gamma(\mathrm{m}+\alpha)}{\Gamma(\mathrm{m})} \mathrm{x}^{-(\mathrm{m}+\alpha)}, \quad \alpha \in \mathbb{R}
$$

But we have to change the definition of the gamma functions when the argument in the numerator is a negative integer. This new definition transforms real functions into complex functions and vice versa, because there is the complex factor $(-1)^{\alpha}=\mathrm{e}^{-\mathrm{i} \alpha \pi}$.

\subsection{Properties of the fractional derivative}

The fractional derivative operator shares the ordinary one in the following general properties

1- Existence and continuity for $\mathrm{m}$ times derivable functions, for any $|\mathrm{n}| \leq \mathrm{m}$.

2- For $\alpha=0$ the result should be the function itself; for $(\alpha \neq 0) \in \mathbb{Z}^{+}$positive integers values it should be equal to the ordinary derivatives and for $(\alpha \neq 0) \in \mathbb{Z}^{-}$the negative integer values it should be equal to ordinary integrations regardless the constant of integration.

3- Composition (or semi group) is satisfied:

$$
\mathrm{D}_{\mathrm{x}}^{\alpha}\left(\mathrm{D}_{\mathrm{x}}^{\beta}[\mathrm{f}(\mathrm{x})]\right)=\mathrm{D}_{\mathrm{x}}^{\alpha+\beta}[\mathrm{f}(\mathrm{x})], \quad \alpha, \beta \in \mathbb{R}
$$

4- Linearity is satisfied

$$
\left.\begin{array}{c}
\mathrm{D}_{\mathrm{x}}^{\alpha}\left\{\left(\lambda_{1}\right) \mathrm{f}(\mathrm{x})+\left(\lambda_{2}\right) \mathrm{g}(\mathrm{x})\right\}=\left(\lambda_{1}\right) \mathrm{D}_{\mathrm{x}}^{\alpha} \mathrm{f}(\mathrm{x})+\left(\lambda_{2}\right) \mathrm{D}_{\mathrm{x}}^{\alpha} \mathrm{g}(\mathrm{x}) \\
\mathrm{D}_{\mathrm{x}}^{\alpha} \mathrm{f}(\mathrm{ax})=\left(\mathrm{a}^{\alpha}\right) \mathrm{D}_{\mathrm{x}}^{\alpha} \mathrm{f}(\mathrm{x})
\end{array}\right\}
$$

5- Subclass, for $\alpha=\mathrm{n} \in \mathbb{N}$ the natural numbers, is satisfied

$$
D_{x}^{\alpha} f(x)=\frac{d^{n}}{d x^{n}} f(x)
$$

6- Zero application of the operator yields the unitary mapping

$$
D_{x}^{0} f(x)=f(x)
$$

7- If $f(x)$ is known function at the point $x$, then we may compute $f(x+h)$ using the fractional Taylor's expansion proposed by (Riemann,

1876) as $\mathrm{f}(\mathrm{x}+\mathrm{h})=\sum_{\mathrm{m}=-\infty}^{\infty} \frac{\mathrm{h}^{\mathrm{m}+\alpha}}{(\mathrm{m}+\alpha)} \mathrm{D}_{\mathrm{x}}^{\mathrm{m}+\alpha} \mathrm{f}(\mathrm{x})$

8- The fractional derivative operator obeys Leibniz rule for taking the derivative of the product of two functions. This property enables us to compute the $\mathrm{n}$-th derivative of an analytic function expressed in terms of Taylor's series as

$$
\begin{aligned}
D_{x}^{\alpha} f(x) g(x) & =\sum_{k=0}^{\infty} \frac{\Gamma(\alpha+1)}{(k+1-\alpha)}\left[D_{x}^{\alpha-k} f(x)\right]\left[D_{x}^{k} g(x)\right] \\
& =\sum_{k=0}^{\infty} \frac{\Gamma(\alpha+1)}{(k+1-\alpha)}\left[D_{x}^{\alpha-k} g(x)\right]\left[D_{x}^{k} f(x)\right]
\end{aligned}
$$

And since $\alpha$ is not integer the upper limit of the sum in (11) is infinite. If one of the functions in the product is a constant, say $\mathrm{g}(\mathrm{x})=\mathrm{C}$, then (11) reduces to

$$
\begin{aligned}
D_{x}^{\alpha}[f(x) g(x)] & \left.=\sum_{k=0}^{\infty} \frac{\Gamma(\alpha+1)}{(k+1-\alpha)}\left[D_{x}^{\alpha-k} f(x)\right]\left[D_{x}^{k} C\right)\right] \\
& =C\left[D_{x}^{\alpha-k} f(x)\right]
\end{aligned}
$$

Since only the $\mathrm{k}=0$ term survives in the series because the integer derivatives of the constant vanish. Thus, property (1) is retained by the generalized Leibniz rule (6), i.e., $\mathrm{D}_{\mathrm{x}}^{\mathrm{k}} \mathrm{C}=0$.

\subsection{The fractional differ integral operator}

In what follows we shall examine the behavior of some elementary functions under the effect of the fractional differ integral operator. The differintegral is an operator that unites the derivative and the integral. Since these two operators complement each other, with the exception of the lower limit required in the integral, this can be done. A differintegral is of a positive order for a derivative and a negative order for an integral. 


\section{Constant function}

We define $\mathrm{A}(\alpha)$ to be the set of constant functions under the real indexed derivative $\mathrm{D}_{\mathrm{x}}^{\alpha}$. As a the second example; let $\mathrm{f}(\mathrm{x})=\mathrm{C} \in \mathrm{A}(\alpha)$ the half derivative can be evaluated as:

$$
\mathrm{D}_{\mathrm{x}}^{1 / 2}[\mathrm{C}]=\mathrm{C} \frac{\Gamma(1)}{\Gamma\left(\frac{1}{2}\right)}\left(\frac{1}{\sqrt{\mathrm{x}}}\right)=\frac{\mathrm{C}}{\sqrt{\pi \mathrm{X}}}
$$

We see that the fractional derivative of a constant function is not zero as usual in the ordinary differentiation. This problem can be solved by defining a local fractional derivative operator.

\section{Monomial function}

Consider the functions $\mathrm{f}(\mathrm{x})=\mathrm{x}^{-1 / 2}$. The half fractional derivative can be computed using Eq. (6) to obtain

$$
\mathrm{D}_{\mathrm{x}}^{1 / 2}\left(\frac{1}{\sqrt{\mathrm{x}}}\right)=\frac{\Gamma\left(\frac{1}{2}\right)}{\Gamma(0)} \mathrm{x}^{-1} \rightarrow 0, \quad \Gamma(0)=\infty
$$

Thus, a particular function is effectively a constant with regard to a certain fractional derivative.

Remark: These two examples demonstrate that there are functions that, under real-indexed derivatives, are additive constants and additive constants that under real-indexed derivatives are functions. These functions that behave as constant under fractional derivative can destroy the composition property of the index of derivation. In fact, let $f(x)$ be a function having a power series representation and assume that there exist derivatives $\mathrm{D}_{\mathrm{x}}^{\mu} \mathrm{f}(\mathrm{x}), \mathrm{D}_{\mathrm{x}}^{\mathrm{v}} \mathrm{f}(\mathrm{x})$ and $\mathrm{D}_{\mathrm{x}}^{\alpha} \mathrm{f}(\mathrm{x})$ with $\alpha=\mu+\mathrm{v}$; if $f(x)$ does not contain function that are constant for the derivative operator $\mathrm{D}_{\mathrm{x}}^{\mu} \mathrm{f}(\mathrm{x})$ and $\mathrm{D}_{\mathrm{x}}^{\mathrm{v}} \mathrm{f}(\mathrm{x})$ then

$$
D_{x}^{\alpha} f(x)=D_{x}^{\mu+v}[f(x)]=D_{x}^{\mu}\left[D_{x}^{v}[f(x)]\right]
$$

\section{Exponential function}

The case of the exponential function is especially simple and gives some clues about the generalization of the derivatives. Following

$$
\begin{aligned}
\mathrm{D}_{\mathrm{x}}^{\alpha}\left[\mathrm{e}^{\alpha \mathrm{x}}\right] & \left.=\lim _{\mathrm{h} \rightarrow 0} \frac{1}{\mathrm{~h}^{\alpha}} \sum_{\mathrm{k}=0}^{\infty}(-1)^{\mathrm{k}}\left(\begin{array}{l}
\alpha \\
\mathrm{k}
\end{array}\right)\left[\mathrm{e}^{\mathrm{ah}(\alpha-\mathrm{k}}\right)\right] \\
\mathrm{D}_{\mathrm{x}}^{\alpha}\left[\mathrm{e}^{\alpha \mathrm{x}}\right] & \left.=\mathrm{e}^{\mathrm{ax}} \lim _{\mathrm{h} \rightarrow 0} \frac{1}{\mathrm{~h}^{\alpha}}(-1)^{\mathrm{k}}\left(\begin{array}{l}
\alpha \\
\mathrm{k}
\end{array}\right)\left[\mathrm{e}^{\mathrm{ah}(\alpha-\mathrm{k}}\right)\right] \\
& =\mathrm{e}^{\mathrm{ax}} \lim _{\mathrm{h} \rightarrow 0} \frac{1}{\mathrm{~h}^{\alpha}}\left(\mathrm{e}^{\alpha \mathrm{h}}-1\right)^{\alpha}=\mathrm{e}^{\alpha} \mathrm{e}^{\mathrm{ax}}
\end{aligned}
$$

It should be notes that the fractional differential operator preserves the exponential function $f(x)=e^{x}$

$$
\mathrm{D}_{\mathrm{x}}^{\alpha}\left[\mathrm{e}^{\mathrm{x}}\right]=\mathrm{e}^{\mathrm{x}}
$$

The above limit exists for any complex number. However, it should be noted that in the substitution of the binomial formula a natural number has been considered. To overcome this difficulty we have to express the exponential function in terms of an infinite series, using (6) yields

$$
\mathrm{D}_{\mathrm{x}}^{\alpha}\left[\mathrm{e}^{\mathrm{x}}\right]=\mathrm{D}_{\mathrm{x}}^{\alpha}\left[\sum_{\mathrm{k}=0}^{\infty} \frac{\mathrm{x}^{\mathrm{k}}}{\mathrm{k} !}\right]=\sum_{\mathrm{k}=0}^{\infty} \frac{\Gamma(\mathrm{k}+1) \mathrm{x}^{\mathrm{k}-\alpha}}{\Gamma(\mathrm{k}+1-\alpha) \mathrm{k} !}=\sum_{\mathrm{k}=0}^{\infty} \frac{\mathrm{x}^{\mathrm{k}-\alpha}}{\Gamma(\mathrm{k}+1-\alpha)}
$$

We can use the fractional differintegral operator to define the generalized exponential function $\mathrm{E}_{\mathrm{x}}^{\alpha}$ as

$$
\mathrm{E}_{\mathrm{x}}^{\alpha}=\mathrm{D}_{\mathrm{x}}^{\alpha}\left[\mathrm{e}^{\mathrm{x}}\right]=\sum_{\mathrm{k}=0}^{\infty} \frac{\mathrm{x}^{\mathrm{k}-\alpha}}{\Gamma(\mathrm{k}+1-\alpha)}
$$

Let us consider, for example the situation when the real-valued index in Eq. (16) is a negative integer $\alpha=-1,-2,-3, \ldots$ Using Eq. (16) we have for $\alpha=-1$

$$
\mathrm{E}_{\mathrm{x}}^{-1}=\mathrm{D}_{\mathrm{x}}^{-1}\left[\mathrm{e}^{\mathrm{x}}\right]=\sum_{\mathrm{k}=0}^{\infty} \frac{\mathrm{x}^{\mathrm{k}+1}}{\Gamma(\mathrm{k}+2)}
$$

So that rendering the series (set $\mathrm{j}=\mathrm{k}+1$ ) we obtain

$$
E_{x}^{-1}=D_{x}^{-1}\left[e^{x}\right]=\sum_{k=0}^{\infty} \frac{x^{j}}{\Gamma(j+1)}=\sum_{j=0}^{\infty} \frac{x^{j}}{\Gamma(j+1)}-1=e^{x}-1
$$


Of course, we can also write the negatively indexed generalized exponential as the first-order integral as

$$
\mathrm{E}_{\mathrm{x}}^{-1}=\mathrm{D}_{\mathrm{x}}^{-1}\left[\mathrm{e}^{\mathrm{x}}\right]=\int_{0}^{\mathrm{x}} \mathrm{e}^{\tau} \mathrm{d} \tau=\mathrm{e}^{\mathrm{x}}-1
$$

We can generalize Eq. (16) to include functions $\mathrm{f}(\mathrm{x})=\mathrm{e}^{\alpha \mathrm{x}}, \alpha \in \mathbb{R}$

$$
\mathrm{D}_{\mathrm{x}}^{\alpha}\left[\mathrm{e}^{\mathrm{ax}}\right]=\mathrm{D}_{\mathrm{x}}^{\alpha}\left[\sum_{\mathrm{k}=0}^{\infty} \frac{(\mathrm{ax})^{\mathrm{k}}}{\mathrm{k} !}\right]=\alpha^{\alpha} \sum_{\mathrm{k}=0}^{\infty} \frac{(\mathrm{ax})^{\mathrm{k}-\alpha}}{\Gamma(\mathrm{k}+1-\alpha)}=\mathrm{a}^{\alpha} \mathrm{E}_{\mathrm{ax}}^{\alpha}
$$

Choose $\alpha=-1$ we can use (17) to write:

$$
\mathrm{D}_{\mathrm{x}}^{\alpha}\left[\mathrm{e}^{-\mathrm{x}}\right]=\mathrm{D}_{\mathrm{x}}^{\alpha}\left[\sum_{\mathrm{k}=0}^{\infty} \frac{(-\mathrm{x})^{\mathrm{k}}}{\mathrm{k} !}\right]=(-1)^{\alpha} \sum_{\mathrm{k}=0}^{\infty} \frac{(-\mathrm{x})^{\mathrm{k}-\alpha}}{\Gamma(\mathrm{k}+1-\alpha)}=\mathrm{e}^{\mathrm{i} \pi \alpha} \mathrm{E}_{-\mathrm{x}}^{\alpha}
$$

which we can further use this to define another generalized exponential function

$$
\begin{aligned}
* \mathrm{E}_{-\mathrm{x}}^{\alpha}=\mathrm{e}^{\mathrm{i} \pi \alpha} \mathrm{E}_{-\mathrm{x}}^{\alpha} & =(-1)^{\alpha} \sum_{\mathrm{k}=0}^{\infty} \frac{(-1)^{\mathrm{k}-\alpha}(\mathrm{x})^{\mathrm{k}-\alpha}}{\Gamma(\mathrm{k}+1-\alpha)} \\
& =\sum_{\mathrm{k}=0}^{\infty} \frac{(-1)^{\mathrm{k}}(\mathrm{x})^{\mathrm{k}-\alpha}}{\Gamma(\mathrm{k}+1-\alpha)}
\end{aligned}
$$

Both Eqs. (17) and (19) make it abundantly clear that the function ${ }^{*} \mathrm{E}_{-\mathrm{x}}^{\alpha}$ is not $\mathrm{E}_{\mathrm{x}}^{\alpha}$ calculated with $-\mathrm{x}$; the new function differs from the old by the phase factor $\mathrm{e}^{\mathrm{i} \pi \alpha}$. Using the property of Eq. (9) we have

$$
\begin{aligned}
\mathrm{D}_{\mathrm{x}}^{\alpha}\left[\mathrm{e}^{-\mathrm{x}}\right] & =(-1)^{\alpha} \mathrm{D}_{\mathrm{x}}^{\alpha}\left[\mathrm{e}^{\tau}\right]_{\mathrm{x}=-\tau} \\
& =(-1)^{\alpha} \mathrm{D}_{\mathrm{x}}^{\alpha}\left[\mathrm{e}^{\tau}\right]_{\tau=-\mathrm{x}}=\mathrm{e}^{\mathrm{i} \pi \alpha} \mathrm{E}_{-\mathrm{x}}^{\alpha}
\end{aligned}
$$

where, $\mathrm{E}_{-\mathrm{x}}^{\alpha}$ is a function in the complex field. For real functions it is convenient to define $* \mathrm{E}_{-\mathrm{x}}^{\alpha}$ as $\mathrm{E}_{-\mathrm{x}}^{\alpha}$ calculated with $-\mathrm{x}$, but in order to do this we need to define the generalized exponential as

$$
\mathrm{E}_{\mathrm{x}}^{\alpha}=|\mathrm{x}|^{-\alpha} \sum_{\mathrm{k}=0}^{\infty} \frac{(\mathrm{x})^{\mathrm{k}}}{(\mathrm{k}+1-\alpha)}
$$

where, it is possible to evaluate this function for both positive and negative values of the independent variable. In general, however, when we are dealing with complex functions we use the first definition of the generalized exponential given by Eq. (16).

\section{Trigonometric functions}

Since $\cos \alpha \mathrm{x} \pm \mathrm{i} \sin \alpha \mathrm{x}=\mathrm{e}^{ \pm \mathrm{i} \alpha \mathrm{x}}$, then we can apply the fractional differintegral operator using the obtained results on the exponential function

$$
\begin{aligned}
& \mathrm{D}_{\mathrm{x}}^{\alpha}(\cos \mathrm{ax}) \pm \mathrm{iD}_{\mathrm{x}}^{\alpha}(\sin \mathrm{ax})=\mathrm{D}_{\mathrm{x}}^{\alpha}\left(\mathrm{e}^{ \pm \mathrm{iax}}\right) \\
& =( \pm a i)^{\alpha} \mathrm{e}^{ \pm \mathrm{iax}}=\mathrm{a}^{\alpha} \mathrm{e}^{ \pm \frac{\mathrm{\alpha} \pi}{2}} \mathrm{e}^{ \pm \mathrm{i} a} \\
& \quad=\mathrm{a}^{\alpha} \cos \left(\mathrm{ax}+\frac{\alpha \pi}{2}\right) \pm \mathrm{ia}^{\alpha} \sin \left(\mathrm{ax}+\frac{\alpha \pi}{2}\right)
\end{aligned}
$$

Solving this system we have the next definition for the sine and cosine derivatives. Equating the real and imaginary parts on each side we obtain

$$
\begin{aligned}
\mathrm{D}_{\mathrm{x}}^{\alpha}(\cos \mathrm{ax}) & =\mathrm{a}^{\alpha} \cos \left(\mathrm{ax}+\frac{\alpha \pi}{2}\right) \\
& =\mathrm{a}^{\alpha}\left[-\sin \frac{\alpha \pi}{2} \sin \mathrm{ax}+\cos \frac{\alpha \pi}{2} \cos \mathrm{ax}\right] \\
\mathrm{D}_{\mathrm{x}}^{\alpha}(\sin \mathrm{ax}) & =\mathrm{a}^{\alpha} \sin \left(\mathrm{ax}+\frac{\alpha \pi}{2}\right) \\
& =\mathrm{a}^{\alpha}\left[-\cos \frac{\alpha \pi}{2} \sin \mathrm{ax}+\sin \frac{\alpha \pi}{2} \cos \mathrm{ax}\right]
\end{aligned}
$$


These expressions can be written in matrix form as:

$$
\left[\begin{array}{l}
\mathrm{D}_{\mathrm{x}}^{\alpha} \cos \mathrm{ax} \\
\mathrm{D}_{\mathrm{x}}^{\alpha} \sin \mathrm{ax}
\end{array}\right]=\mathrm{a}^{\alpha}\left[\begin{array}{cc}
-\sin \frac{\alpha \pi}{2} & \cos \frac{\alpha \pi}{2} \\
\cos \frac{\alpha \pi}{2} & \sin \frac{\alpha \pi}{2}
\end{array}\right]\left[\begin{array}{l}
\sin \mathrm{ax} \\
\cos \mathrm{ax}
\end{array}\right]
$$

\section{Generalized trigonometric functions}

The generalized complex exponential function can be used as:

$$
\begin{aligned}
& \mathrm{D}_{\mathrm{x}}^{\alpha}(\cos \mathrm{x}) \pm \mathrm{iD}_{\mathrm{x}}^{\alpha}(\sin \mathrm{x})=\mathrm{E}_{\mathrm{ix}}^{\alpha} \\
& =\frac{1}{2}\left\{\mathrm{E}_{\mathrm{ix}}^{\alpha}+\mathrm{E}_{-\mathrm{ix}}^{\alpha}\right\}+\frac{1}{2 \mathrm{i}}\left\{\mathrm{E}_{\mathrm{ix}}^{\alpha}+\mathrm{E}_{-\mathrm{ix}}^{\alpha}\right\}
\end{aligned}
$$

From the real part of Eq. (22) we obtain the equation for the generalized cosine and sine functions as

$$
\begin{aligned}
& D_{\mathrm{x}}^{\alpha}(\cos \mathrm{x})=\cos _{\alpha} \mathrm{x}=\frac{1}{2}\left\{\mathrm{E}_{\mathrm{ix}}^{\alpha}+\mathrm{E}_{-\mathrm{i} \mathrm{x}}^{\alpha}\right\} \\
& \mathrm{D}_{\mathrm{x}}^{\alpha}(\sin \mathrm{x})=\sin _{\alpha} \mathrm{x}=\frac{1}{2 \mathrm{i}}\left\{\mathrm{E}_{\mathrm{ix}}^{\alpha}-\mathrm{E}_{-\mathrm{ix}}^{\alpha}\right\}
\end{aligned}
$$

We can also express the generalized sine and generalized cosine functions in series form using the series definition of the generalized exponential. The obtained generalized cosine function reads

$$
\begin{aligned}
\cos _{\alpha} \mathrm{x} & =\frac{1}{2}\left\{\mathrm{E}_{\mathrm{ix}}^{\alpha}+\mathrm{E}_{-\mathrm{ix}}^{\alpha}\right\}=\sum_{\mathrm{k}=0}^{\infty} \frac{(-1)^{\mathrm{k}-\alpha}}{2 \Gamma(\mathrm{k}+1-\alpha)}\left[\mathrm{e}^{\frac{\mathrm{i}(\mathrm{k}-\alpha) \pi}{2}}+\mathrm{e}^{\frac{\mathrm{i}(\mathrm{k}-\alpha) \pi}{2}}\right] \\
& =\sum_{\mathrm{k}=0}^{\infty} \frac{(\mathrm{x})^{\mathrm{k}-\alpha}}{\Gamma(\mathrm{k}+1-\alpha)} \cos \left(\frac{(\mathrm{k}-\alpha) \pi}{2}\right) \\
\sin _{\alpha} \mathrm{x} & =\frac{1}{2}\left\{\mathrm{E}_{\mathrm{ix}}^{\alpha}+\mathrm{E}_{-\mathrm{ix}}^{\alpha}\right\}=\sum_{\mathrm{k}=0}^{\infty} \frac{(\mathrm{x})^{\mathrm{k}-\alpha}}{2 \Gamma(\mathrm{k}+1-\alpha)}\left[\mathrm{e}^{\frac{\mathrm{i}(\mathrm{k}-\alpha) \pi}{2}}-\mathrm{e}^{-\frac{\mathrm{i}(\mathrm{k}-\alpha) \pi}{2}}\right] \\
& =\sum_{\mathrm{k}=0}^{\infty} \frac{(\mathrm{x})^{\mathrm{k}-\alpha}}{\Gamma(\mathrm{k}+1-\alpha)} \sin \left(\frac{(\mathrm{k}-\alpha) \pi}{2}\right)
\end{aligned}
$$

The above results agree with the ordinary differentiation and integration when is positive and negative integers respectively and when $\quad \alpha=0$ yields the ordinary function itself.

\section{Ordinary differentiation of the generalized trigonometric functions}

It is useful to study the derivatives of the generalized trigonometric functions in order to understand how these periodic functions differ from those in the standard form. Consider the first-order time derivative of the generalized cosine function:

$$
\begin{aligned}
\frac{\mathrm{d}}{\mathrm{dx}}\left[\cos _{\alpha} \mathrm{x}\right] & =\sum_{\mathrm{k}=0}^{\infty} \frac{(\mathrm{k}-\alpha)(\mathrm{x})^{\mathrm{k}-\alpha-1}}{\Gamma(\mathrm{k}+1-\alpha)} \cos \left(\frac{(\mathrm{k}-\alpha) \pi}{2}\right) \\
& =\sum_{\mathrm{k}=0}^{\infty} \frac{(\mathrm{x})^{\mathrm{k}-\alpha-1}}{\Gamma(\mathrm{k}-\alpha)} \cos \left(\frac{(\mathrm{k}-\alpha) \pi}{2}\right)
\end{aligned}
$$

So that re-indexing the series $($ set $\mathrm{k}=\mathrm{j}+1)$ we get

$$
\frac{d}{d x}\left[\cos _{\alpha} x\right]=\sum_{j=-1}^{\infty} \frac{(x)^{j-\alpha}}{\Gamma(j+1-\alpha)} \cos \left(\frac{(j+1-\alpha) \pi}{2}\right)
$$

Separating the $\mathrm{j}=-1$ term from the series and using the trigonometric identity:

$$
\cos \left(\frac{(j+1-\alpha) \pi}{2}\right)=-\sin \left(\frac{(j-\alpha) \pi}{2}\right)
$$

yields 


$$
\frac{d}{d x}\left[\cos { }_{\alpha} x\right]=-\sin _{\alpha} x+\frac{\cos \left(\frac{\alpha \pi}{2}\right)}{\Gamma(-\alpha)} \frac{1}{x^{\alpha+1}}
$$

where, we have used Eq. (26) to replace the series. We see that the formal relation resulting from the derivative of the generalized cosine differs from that of the derivative of the ordinary cosine by a term that decays as an inverse power law in the independent variable. Thus, as $x \rightarrow \infty$; the formal relation for the two derivatives approaches one another:

$$
\lim _{x \rightarrow \infty}\left\{\frac{d}{d x}\left[\cos _{\alpha} x\right]\right\}=-\sin x
$$

The inverse power-law form of the term in Eq. (27) is quite suggestive, since the memory in dynamical processes that make it impossible to join the microscopic and macroscopic descriptions of complex phenomena are exactly of this inverse power-law form.

Let us now examine the derivative of the generalized sine function

$$
\begin{aligned}
\frac{\mathrm{d}}{\mathrm{dx}}\left[\sin _{\alpha} \mathrm{x}\right] & =\sum_{\mathrm{k}=0}^{\infty} \frac{(\mathrm{k}-\alpha)(\mathrm{x})^{\mathrm{k}-\alpha-1}}{\Gamma(\mathrm{k}+1-\alpha)} \sin \left(\frac{(\mathrm{k}-\alpha) \pi}{2}\right) \\
& =\sum_{\mathrm{k}=0}^{\infty} \frac{(\mathrm{x})^{\mathrm{k}-\alpha-1}}{\Gamma(\mathrm{k}-\alpha)} \sin \left(\frac{(\mathrm{k}-\alpha) \pi}{2}\right)
\end{aligned}
$$

So that re -indexing the series (set $\mathrm{k}=\mathrm{j}+1)$ we obtain

$$
\frac{d}{d x}\left[\sin _{\alpha} x\right]=\sum_{j=-1}^{\infty} \frac{(x)^{j-\alpha}}{\Gamma(j+1-\alpha)} \cos \left(\frac{(j+1-\alpha) \pi}{2}\right)
$$

Separating the $\mathrm{j}=-1$ term from the series and using the trigonometric identity:

$$
\sin \left(\frac{(j+1-\alpha) \pi}{2}\right)=\cos \left(\frac{(j-\alpha) \pi}{2}\right)
$$

yields

$$
\frac{d}{d x}\left[\sin { }_{\alpha} x\right]=\cos _{\alpha} x+\frac{\sin \left(\frac{\alpha \pi}{2}\right)}{\Gamma(-\alpha)} \frac{1}{x^{\alpha+1}}
$$

where, we have used Eq. (29) to replace the series. We see that the formal relation resulting from the derivative of the generalized sine differs from that of the derivative of the ordinary sine by a term that decays as an inverse power law in the in dependent variable. Thus, as $x \rightarrow \infty$; the formal relations for the two derivatives approach one another

$$
\lim _{x \rightarrow \infty}\left\{\frac{d}{d x}[\sin \alpha x]=\cos x\right.
$$

\section{Fractional rotation matrix}

We have examined what happens to a generalized trigonometric function when we take an ordinary derivative. Now let us examine what happens to an ordinary trigonometric function when we take a fractional derivative. Consider the fractional derivative of the sine and cosine functions

$$
\begin{aligned}
\mathrm{D}_{\mathrm{x}}^{\alpha}[\sin \mathrm{ax}] & =\frac{1}{2 \mathrm{i}}\left\{\mathrm{D}_{\mathrm{x}}^{\alpha}\left[\mathrm{e}^{\mathrm{iax}}\right]-\mathrm{D}_{\mathrm{x}}^{\alpha}\left[\mathrm{e}^{-\mathrm{iax}}\right]\right\} \\
& =\frac{\mathrm{a}^{\alpha}}{2 \mathrm{i}}\left\{\mathrm{e}^{\frac{\mathrm{i} \alpha \pi}{2}} \mathrm{E}_{\mathrm{iax}}^{\alpha}-\mathrm{e}^{\frac{\mathrm{i} \alpha \pi}{2}} \mathrm{E}_{-\mathrm{iax}}^{\alpha}\right\}
\end{aligned}
$$

So that using the Euler relations for both the exponential and generalized exponential and combining terms we obtain

$$
\mathrm{D}_{\mathrm{x}}^{\alpha}(\sin \mathrm{x})=\cos \frac{\alpha \pi}{2} \sin \alpha \mathrm{x}+\sin \frac{\alpha \pi}{2} \cos _{\alpha} \mathrm{x}
$$

Similarly for the cosine function we have

$$
D_{x}^{\alpha}(\cos x)=-\sin \frac{\alpha \pi}{2} \sin _{\alpha} x+\cos \frac{\alpha \pi}{2} \cos _{\alpha} x
$$


A geometrical interpretation Eq. (31) and (32) can be obtained by introducing the rotation matrix $\mathbf{R}$ as

$$
\mathbf{R}=\left[\begin{array}{cc}
\cos \frac{\alpha \pi}{2} & \sin \frac{\alpha \pi}{2} \\
-\sin \frac{\alpha \pi}{2} & \cos \frac{\alpha \pi}{2}
\end{array}\right]
$$

and the vector

$$
\mathrm{V}_{0}=\left[\begin{array}{c}
\sin \mathrm{x} \\
\cos \mathrm{x}
\end{array}\right], \quad \mathrm{V}_{\alpha}=\left[\begin{array}{c}
\sin _{\alpha} \mathrm{x} \\
\cos _{\alpha} \mathrm{x}
\end{array}\right]
$$

So that we can write

$$
\mathrm{D}_{\mathrm{x}}^{\alpha}\left[\mathrm{V}_{0}\right]=\mathbf{R}\left[\mathrm{V}_{\alpha}\right]
$$

Equation (34) represents more general rotation transform. The generalized functions reduce to their ordinary counterparts when $\alpha=0$. It seems that the length of the rotation matrix is unity whatever the value of $\alpha$ is.

\section{Binomial function}

Given the binomial function $\mathrm{f}(\mathrm{x})=(\mathrm{a}+\mathrm{bx})^{\mathrm{a}-1}$, applying the fractional derivative we obtain

$$
\begin{aligned}
\mathrm{D}_{\mathrm{x}}^{\alpha}[\mathrm{a}+\mathrm{bx}]^{\alpha-1} & =\sum_{\mathrm{k}=0}^{\infty} \frac{\Gamma(\alpha+1)}{\Gamma(\mathrm{k}+1-\alpha)} \\
& \times \mathrm{D}_{\mathrm{x}}^{\alpha-\mathrm{k}}\left[\mathrm{x}^{0}\right] \mathrm{D}_{\mathrm{x}}^{\mathrm{k}}[\alpha+\mathrm{bx}]^{\alpha-1}
\end{aligned}
$$

So that in terms of the fractional derivative of a constant and the integer $\mathrm{k}$ derivative of the function we have

$$
\begin{aligned}
\mathrm{D}_{\mathrm{x}}^{\alpha}[\mathrm{a}+\mathrm{bx}]^{\alpha-1} & =\sum_{\mathrm{k}=0}^{\infty} \frac{\Gamma(\alpha+1)}{\Gamma(\mathrm{k}+1-\alpha)} \frac{\mathrm{x}^{\mathrm{k}-\alpha}}{(\mathrm{k}-\alpha+1)}(\alpha-1) \\
& \times(\alpha-2) \ldots .(\alpha-\mathrm{k}-1) \mathrm{b}^{\mathrm{k}}[\mathrm{a}+\mathrm{bx}]^{\alpha-1-\mathrm{k}}
\end{aligned}
$$

Using the relations:

$$
\begin{aligned}
& \Gamma(\alpha)=(\alpha-1)(\alpha-2) \ldots(\alpha-\mathrm{k}-1) \Gamma(\alpha-\mathrm{k}) \\
& \Gamma(\alpha-\mathrm{k})(\mathrm{k}+1-\alpha)=\frac{\pi}{\sin (\alpha-\mathrm{k}) \pi}
\end{aligned}
$$$$
\sin (\alpha-\mathrm{k}) \pi=(-1)^{\mathrm{k}} \sin \alpha \pi
$$

The above relation can be written as:

$$
\begin{aligned}
\mathrm{D}_{\mathrm{x}}^{\alpha}[\mathrm{a}+\mathrm{bx}]^{\alpha-1}= & \Gamma(\alpha) \frac{[\alpha+\mathrm{bx}]^{\alpha-1} \sin (\pi \alpha)}{\pi \mathrm{x}^{\alpha}} \\
& \times \sum_{\mathrm{k}=0}^{\infty} \frac{\Gamma(\alpha+1)}{\Gamma(\mathrm{k}+1-\alpha)} \frac{(-\mathrm{bx})^{\mathrm{k}}}{[\mathrm{a}+\mathrm{bx}]^{\mathrm{k}}}
\end{aligned}
$$

The binomial relation

$$
(1+\mathrm{z})^{\alpha}=\sum_{\mathrm{k}=0}^{\infty} \frac{\Gamma(\alpha+1)}{\Gamma(\mathrm{k}+1-\alpha)} \mathrm{z}^{\mathrm{k}}
$$

Setting

$$
z=\frac{(-b x)}{[a+b x]}
$$

yields

$$
\mathrm{D}_{\mathrm{x}}^{\alpha}[\mathrm{a}+\mathrm{bx}]^{\alpha-1}=\frac{\mathrm{a}^{\alpha} \sin (\pi \alpha)}{\pi \mathrm{x}^{\alpha}} \frac{\Gamma(\alpha)}{\mathrm{a}+\mathrm{bx}}
$$




\section{Riemann-Louville differintegral operator}

The development of the FC theory is due to the contributions of many mathematicians such as Euler, Liouville, Riemann and Letnikov. Several definitions of a fractional derivative have been proposed. These definitions include Riemann-Louville, Grunwald-Letnikov, Weyl, Caputo, Marched and Rises fractional derivatives, (Miller and Ross, 1993; Riewe, 1996; Oldham and Spanier, 1974; Baleanu, 2008). Riemann-Louville derivative is the most used generalization of the derivative. It is based on the direct generalization of Cauchy's formula for calculating an n-fold or repeated integral. If the first integral of a function, which must equal to deriving it to -1 , is as follows

$$
D^{-1} f(x)=\int_{0}^{x} f(t) d t
$$

The calculation of the second can be simplified by interchanging the integration order

$$
\begin{aligned}
D^{-2} f(x) & =\int_{0}^{x} \int_{t_{1}}^{x} f\left(t_{1}\right) d t_{2} d t_{1}= \\
& =\int_{t_{1}}^{x} f\left(t_{1}\right) d t_{1} \int_{t_{1}}^{x} d t_{2}=\int_{0}^{x} f(t)(x-t) d t
\end{aligned}
$$

This method can be applied repeatedly, resulting in the following formula for calculating iterated integrals

$$
D^{-n} f(x)=\frac{1}{(n-1) !} \int_{a}^{x} f(t)(x-t)^{n-1} d t
$$

Now this can be easily generalized to non-integer values, in what is the Riemann-Louville derivative

$$
D^{\alpha} f(x)=\frac{1}{\Gamma(-\alpha)} \int_{0}^{x} f(t)(x-t)^{-\alpha-1} d t
$$

where $\Gamma$ represents the Euler gamma function. Note however that in the above formulas the election of 0 as the lower limit of integration has been arbitrary and any other number could be chosen. Generally, the election of the integration limits in this and other generalizations of the derivative is indicated with subscripts. The Riemann-Louville derivative with the lower integration limit a would be

$$
{ }_{a} D^{\alpha} f(x)=\frac{1}{\Gamma(-\alpha)} \int_{a}^{x} f(t)(x-t)^{-\alpha-1} d t
$$

The problem with this generalization is that if the real part of is positive integer or zero the integral diverges. So it only can be used to calculate generalized integrals. However, this can be solved easily by deriving first by ordinary derivative more than the amount necessary, thus making the remaining necessary differentiation negative and then applying the generalized derivative for completing the rest in which will be a negative differentiation:

$$
{ }_{\mathrm{a}} \mathrm{D}^{\alpha} \mathrm{f}(\mathrm{x})=\mathrm{D}^{\mathrm{n}}\left[{ }_{\mathrm{a}} \mathrm{D}_{\mathrm{x}}^{\alpha-\mathrm{n}} \mathrm{f}(\mathrm{x})\right]
$$

Now, we can easily write the right and the left Riemann-Liouville fractional derivatives, in brief denoted by RRLFD and LRLFD respectively as

$$
\begin{aligned}
& { }_{a} D_{x}^{\alpha} f(x)=\frac{1}{\Gamma(n-\alpha)}\left(\frac{d}{d x}\right)^{n} \int_{a}^{x} f(t)(x-t)^{n-\alpha-1} d t \\
& { }_{x} D_{b}^{\alpha} f(x)=\frac{1}{\Gamma(n-\alpha)}\left(-\frac{d}{d x}\right)^{n} \int_{x}^{b} f(t)(x-t)^{n-\alpha-1} d t
\end{aligned}
$$

where, $\alpha$ is the order of the derivative such that $n-1 \leq \alpha<\mathrm{n}$. If $\alpha$ is an integer, these derivatives are defined in the usual sense, i.e.,

$$
{ }_{a} D_{x}^{\alpha} f(x)=\left(\frac{d}{d x}\right)^{\alpha} f(x), \quad{ }_{x} D_{b}^{\alpha} f(x)=\left(-\frac{d}{d x}\right)^{\alpha} f(x)
$$

Note that in the literature the Riemann-Louville fractional derivative generally means the LRLFD. From physical point of view, if $\mathrm{x}$ is considered as a time scale, the RRLFD represents an operation performed on the future state of the process $\mathrm{f}(\mathrm{x})$. This derivative has generally been neglected with the assumption that the present state of a process does not depend on the results of its future development. However, the derivations to follow will show that both derivatives naturally occur in a problem of fractional calculus of variations.

The fractional operator ${ }_{a} D_{x}^{\alpha}$ can be written as,

$$
{ }_{\mathrm{a}} \mathrm{D}_{\mathrm{x}}^{\alpha}=\left(\frac{\mathrm{d}^{\mathrm{n}}}{\mathrm{dx^{ \textrm {n } }}}\right){ }_{\mathrm{a}} \mathrm{D}_{\mathrm{x}}^{\alpha-\mathrm{n}}
$$


where the number of additional differentiations $\mathrm{n}$ is equal to $[\alpha]+1$, where $[\alpha]$ is the whole part of the operator ${ }_{a} D_{x}^{\alpha}$ is a generalization of differential and integral operators and can be introduced as follows

$$
\mathrm{D}_{\mathrm{x}}^{\alpha}= \begin{cases}\frac{\mathrm{d}^{\alpha}}{\mathrm{dx}^{\alpha}}, & \text { fractional differentiation mapping } \\ 1, & \text { fractional unitary mapping } \\ \int_{\mathrm{a}}^{\mathrm{x}} \mathrm{dt}^{-\alpha} & \text { fractional int egration mapping }\end{cases}
$$

\section{Fractional Euler-Lagrange equation}

The motion of the conservative system from time $t_{1}$ to time $t_{2}$ is such the line integral below (called the action) is an extremum:

$$
\mathcal{J}=\int_{\mathrm{t}_{1}}^{\mathrm{t}_{2}} \mathcal{L}\left(\mathrm{q}_{\mathrm{i}},{ }_{\mathrm{a}} \mathrm{D}_{\mathrm{t}}^{\alpha \mathrm{i}} \mathrm{q}_{\mathrm{i}},{ }_{\mathrm{a}} \mathrm{D}_{\mathrm{t}}^{\beta \mathrm{i}} \mathrm{q}_{\mathrm{i}}, \mathrm{t}\right) \mathrm{dt}, \mathrm{i}=1,2, \ldots, \mathrm{n}
$$

where $\mathcal{L}\left(q_{i},{ }_{a} D_{t}^{\alpha i} q_{i},{ }_{a} D_{t}^{\beta i} q_{i}, t\right)$ is a function of the generalized coordinates, left and the right fractional derivatives of the generalized coordinates and time has a stationary value for the actual path of the motion. We wish to find a particular path $\mathrm{q}_{\mathrm{i}}(\mathrm{t})$ such that the line integral of the function $\mathcal{L}$ between $t_{1}$ and $t_{2}$ has a stationary value relative to paths differing infinitesimally from the correct function $q_{i}(t)$. We consider only such varied paths for which $\mathrm{q}_{\mathrm{i}}\left(\mathrm{t}_{1}\right)=\mathrm{q}_{\mathrm{i} 1}$ and $\mathrm{q}_{\mathrm{i}}\left(\mathrm{t}_{2}\right)=\mathrm{q}_{\mathrm{i} 2}$ these paths differ only in the functional relation between $\mathrm{q}_{\mathrm{i}}$ and $\mathrm{t}$. To find the stationary points, the variation of the action must be zero relative to some particular set of neighboring paths labeled by infinitesimal parameter $\varepsilon$. Such a set of paths might be denoted by $\mathrm{q}_{\mathrm{i}}(\mathrm{t}, \varepsilon)$ with $\mathrm{q}_{\mathrm{i}}(\mathrm{t}, 0)$ representing the correct path. If we select any function $\eta(\mathrm{t})$ that vanishes at $\mathrm{t}=\mathrm{t}_{1}$ and $\mathrm{t}=\mathrm{t}_{2}$ then the possible set of the varied paths are given by:

$$
\mathrm{q}_{\mathrm{i}}(\mathrm{t}, \varepsilon)=\mathrm{q}_{\mathrm{i}}(\mathrm{t}, 0)+\varepsilon \eta(\mathrm{t})
$$

For any such parametric family of curves, Eq. (42) can be written as:

$$
\mathcal{J}(\varepsilon)=\int_{\mathrm{t}_{1}}^{\mathrm{t}_{2}} \mathcal{L}\left(\mathrm{q}_{\mathrm{i}}(\mathrm{t}, \varepsilon),{ }_{\mathrm{a}} \mathrm{D}_{\mathrm{t}}^{\alpha \mathrm{i}} \mathrm{q}_{\mathrm{i}}(\mathrm{t}, \varepsilon),{ }_{\mathrm{a}} \mathrm{D}_{\mathrm{t}}^{\beta \mathrm{i}} \mathrm{q}_{\mathrm{i}}(\mathrm{t}, \varepsilon), \mathrm{t}\right) \mathrm{dt},
$$

With the condition for obtaining the stationary points

$$
\left(\frac{\mathrm{d} \mathcal{J}(\varepsilon)}{\mathrm{d} \varepsilon}\right)_{\varepsilon=0}=0
$$

By the usual method of differentiating under the integral sign, we find using Eq. (43)

$$
\begin{aligned}
& \int_{t_{1}}^{t_{2}}\left({ }_{t_{1}} D_{t}^{\alpha i} q_{i}\right) d t=q_{i} \mid \begin{array}{l}
t_{2} \\
t_{1}
\end{array} \\
& \int_{\mathrm{t}_{1}}^{\mathrm{t}_{2}}\left[\frac{\partial \mathcal{L}}{\partial \mathrm{q}_{\mathrm{i}}}\left(\frac{\partial \mathrm{q}_{\mathrm{i}}}{\partial \varepsilon}\right)_{0}+\frac{\partial \mathcal{L}}{\partial_{\mathrm{t}_{1}} \mathrm{D}_{\mathrm{t}}^{\alpha \mathrm{i}} \mathrm{q}_{\mathrm{i}}}\left(\frac{\partial_{\mathrm{t}_{1}} \mathrm{D}_{\mathrm{t}}^{\alpha \mathrm{i}} \mathrm{q}_{\mathrm{i}}}{\partial \varepsilon}\right)_{0}\right. \\
& \left.+\frac{\partial \mathcal{L}}{\partial_{\mathrm{t}} \mathrm{D}_{\mathrm{t}_{2}}^{\beta \mathrm{i}} \mathrm{q}_{\mathrm{i}}}\left(\frac{\partial_{\mathrm{t}} \mathrm{D}_{\mathrm{t}_{2}}^{\beta \mathrm{i}} \mathrm{q}_{\mathrm{i}}}{\partial \varepsilon}\right)_{0}\right] \mathrm{dt}=0
\end{aligned}
$$

Integrating the second and the third terms in the integrand by parts (remember that the integration is now performed using the fractional integration) yields:

$$
\begin{gathered}
\int_{t_{1}}^{t_{2}} \frac{\partial \mathcal{L}}{\partial_{t_{1}} D_{t_{2}}^{\alpha i} q_{i}}\left(\frac{\partial_{t_{1}} D_{t}^{\alpha i} q_{i}}{\partial \varepsilon}\right)_{0} d t=\left\{\left.\frac{\partial \mathcal{L}}{\partial_{t_{1}} D_{t}^{\alpha i} q_{i}}\right|_{t_{1}} ^{t_{2}}\right. \\
\left.+\int_{t_{1}}^{t 2} D_{t_{2}}^{\alpha i}\left(\frac{\partial \mathcal{L}}{\partial{ }_{\alpha} D_{t}^{\alpha i} q}\right)\right\}\left(\frac{\partial q_{i}}{\partial \varepsilon}\right)_{0} d t
\end{gathered}
$$




$$
\begin{array}{r}
\int_{\mathrm{t}_{1}}^{\mathrm{t}_{2}} \frac{\partial \mathcal{L}}{\partial_{\mathrm{t}_{1}} \mathrm{D}_{\mathrm{t}_{2}}^{\alpha \mathrm{i}} \mathrm{q}_{\mathrm{i}}}\left(\frac{\partial_{\mathrm{t}} \mathrm{D}_{\mathrm{t}_{2}}^{\beta \mathrm{i}} \mathrm{q}_{\mathrm{i}}}{\partial \varepsilon}\right)_{0} \mathrm{dt}=\left\{\left.\frac{\partial \mathcal{L}}{\partial_{\mathrm{t}} \mathrm{D}_{\mathrm{t}}^{\beta \mathrm{i}} \mathrm{q}_{\mathrm{i}}}\right|_{\mathrm{t}_{1}} ^{\mathrm{t}_{2}}\right. \\
\left.+\int_{\mathrm{t}_{1}}^{\mathrm{t}_{2}} \mathrm{D}_{\mathrm{t}}^{\beta \mathrm{i}}\left(\frac{\partial \mathcal{L}}{\partial_{\mathrm{t}} \mathrm{D}_{\mathrm{t}_{2}}^{\beta \mathrm{i}} \mathrm{q}_{\mathrm{i}}}\right)\right\}\left(\frac{\partial \mathrm{q}_{\mathrm{i}}}{\partial \varepsilon}\right)_{0} \mathrm{dt}
\end{array}
$$

The conditions on all the varied curves are that they pass through the points $\left(\mathrm{q}_{\mathrm{i}}, \mathrm{t}_{1}\right),\left(\mathrm{q}_{\mathrm{i}}, \mathrm{t}_{2}\right)$ and hence the partial derivatives $\frac{\partial \mathrm{q}_{\mathrm{i}}}{\partial \varepsilon}$ at $\mathrm{t}_{1}$ and $\mathrm{t}_{2}$ must vanish. Therefore

$\int_{\mathrm{t}_{1}}^{\mathrm{t}_{2}}\left[\frac{\partial \mathcal{L}}{\partial \mathrm{q}_{\mathrm{i}}}+{ }_{\mathrm{t}} \mathrm{D}_{\mathrm{t}_{2}}^{\alpha \mathrm{i}}\left(\frac{\partial \mathcal{L}}{\partial_{\mathrm{a}} \mathrm{D}_{\mathrm{t}}^{\alpha \mathrm{i}} \mathrm{q}_{\mathrm{i}}}\right)+{ }_{\mathrm{t}_{1}} \mathrm{D}_{\mathrm{t}}^{\beta \mathrm{i}}\left(\frac{\partial \mathcal{L}}{\partial_{\mathrm{t}} \mathrm{D}_{\mathrm{t}_{2}}^{\beta i} \mathrm{q}_{\mathrm{i}}}\right)\right]\left(\frac{\partial \mathrm{q}_{\mathrm{i}}}{\partial \varepsilon}\right)_{0} \mathrm{dt}=0$

The quantity $\left(\frac{\partial \mathrm{q}_{\mathrm{i}}}{\partial}\right)$ is a function of time $\mathrm{t}$ that is arbitrary except for the continuity and end point conditions. Using the fundamental lemma of calculies of variation

$$
\int_{t_{1}}^{t_{2}} M(t) \eta(t) d t=0
$$

For any arbitrary function $\eta(t)$ continuous through the second derivative, then $M(t)$ must identically vanish in the interval $\left(t_{1}, t_{2}\right)$. It therefore follows that $\mathcal{J}$ can have stationary values only if

$$
\left[\frac{\partial \mathcal{L}}{\partial \mathrm{q}_{\mathrm{i}}}+{ }_{\mathrm{t}} \mathrm{D}_{\mathrm{t}_{2}}^{\alpha \mathrm{i}}\left(\frac{\partial \mathcal{L}}{\partial_{\mathrm{a}} \mathrm{D}_{\mathrm{t}}^{\alpha \mathrm{i}} \mathrm{q}_{\mathrm{i}}}\right)+{ }_{\mathrm{t}_{1}} \mathrm{D}_{\mathrm{t}}^{\beta \mathrm{i}}\left(\frac{\partial \mathcal{L}}{\partial_{\mathrm{t}} \mathrm{D}_{\mathrm{t}_{2}}^{\beta \mathrm{i}} \mathrm{q}_{\mathrm{i}}}\right)\right]=0
$$

Equation (48) is the fractional Euler-Lagrange equation. Note that for fractional calculus of variation problems the resulting Euler-Lagrange equation contains both the LRLFD and the RRLFD. This is expected since the optimum function must satisfy both terminal conditions. Further,

for $\alpha=\beta=1$, we have ${ }_{t_{1}} D_{t}^{\alpha}=\frac{d}{d t}$, and ${ }_{t} D_{t_{2}}^{\alpha}=-\frac{d}{d t}$, thus equation (48) reduces to the standard Euler- Lagrange as

$$
\left[\frac{\partial \mathcal{L}}{\partial \mathbf{q}_{i}}-\frac{\mathbf{d}}{\mathbf{d t}}\left(\frac{\partial \mathcal{L}}{\partial \mathbf{q}_{i}}\right)\right]=\mathbf{O}
$$

Where $\mathcal{L}(\mathrm{p}, \mathrm{q}, \mathrm{t})$ the Lagrangian of the system is a function of the generalized coordinates $\mathrm{q}$, the generalized momenta $\mathrm{q}$ and time $\mathrm{t}$. Since we have two kinds of derivatives namely LRLFD and RRLFD, so we can define two independent generalized fractional momenta as

$$
\mathrm{p}_{\alpha}={ }_{\mathrm{a}} \mathrm{D}_{\mathrm{t}}^{\alpha} \mathrm{q}, \quad \mathrm{p}_{\beta}={ }_{\mathrm{t}} \mathrm{D}_{\mathrm{b}}^{\beta} \mathrm{q}
$$

Thus the fractional Euler-Lagrange equation is obtained by replacing the classical integral derivatives with the fractional ones as

$$
\begin{aligned}
& \mathcal{L}\left(\mathrm{q}_{\mathrm{i}},{ }_{\mathrm{a}} \mathrm{D}_{\mathrm{t}}^{\alpha} \mathrm{q}_{\mathrm{i}},{ }_{\mathrm{a}} \mathrm{D}_{\mathrm{t}}^{\beta} \mathrm{q}, \mathrm{t}\right), \mathrm{t} \in[\mathrm{a}, \mathrm{b}] \\
& \frac{\partial \mathcal{L}}{\partial \mathrm{q}}+{ }_{\mathrm{t}} \mathrm{D}_{\mathrm{b}}^{\alpha}\left(\frac{\partial \mathcal{L}}{\partial_{\alpha} \mathrm{D}_{\mathrm{t}}^{\alpha} \mathrm{q}}\right)+{ }_{\alpha} \mathrm{D}_{\mathrm{t}}^{\beta}\left(\frac{\partial \mathcal{L}}{\partial_{\mathrm{t}} \mathrm{D}_{\mathrm{b}}^{\beta} \mathrm{q}}\right)=0
\end{aligned}
$$

and the transversality conditions:

$$
{ }_{\mathrm{t}} \mathrm{D}_{\mathrm{b}}^{\alpha-1}\left(\frac{\partial \mathcal{L}}{\partial_{\mathrm{a}} \mathrm{D}_{\mathrm{t}}^{\alpha} \mathrm{q}}\right)-\left.{ }_{\mathrm{a}} \mathrm{D}_{\mathrm{t}}^{\beta-1}\left(\frac{\partial \mathcal{L}}{\partial_{\mathrm{t}} \mathrm{D}_{\mathrm{t}}^{\alpha} \mathrm{q}}\right) \eta(\mathrm{t})\right|_{\alpha} ^{\mathrm{b}}=0
$$

where ${ }_{t} D_{b}^{\alpha-1}$ denotes the fractional integral of order $\alpha-1$, see Agrawal, (2007) for the proof. 


\section{The fractional Hamilton's equations}

An important property of classical Hamiltonian systems is that they are solutions of a variation principle, called the Hamilton least action principle. We can also build the fractional canonical Hamiltonian from its classical form as

$$
\begin{aligned}
\mathcal{H}=p \dot{\mathrm{q}}-\mathcal{L} & =\mathrm{p}_{\mathrm{a}}\left({ }_{\mathrm{a}} \mathrm{D}_{\mathrm{t}}^{\alpha} \mathrm{q}\right)+\mathrm{p}_{\beta}\left({ }_{\mathrm{t}} \mathrm{D}_{\mathrm{b}}^{\beta} \mathrm{q}\right) \\
& -\mathcal{L}\left(\mathrm{q},{ }_{\mathrm{a}} \mathrm{D}_{\mathrm{t}}^{\alpha} \mathrm{q},{ }_{\mathrm{t}} \mathrm{D}_{\mathrm{b}}^{\beta}, \mathrm{q} ; \mathrm{t}\right)
\end{aligned}
$$

where $\mathcal{L}$ is the generalized Lagrangian function of the form $\mathcal{L}\left(\mathrm{q},{ }_{\alpha} \mathrm{D}_{\mathrm{t}}^{\alpha} \mathrm{q},{ }_{\mathrm{t}} \mathrm{D}_{\mathrm{b}}^{\beta} \mathrm{q} ; \mathrm{t}\right)$.

Taking total differential of Eq. (53) yields:

$$
\mathrm{d} \mathcal{H}=\mathrm{dp}_{\alpha}\left({ }_{\mathrm{a}} \mathrm{D}_{\mathrm{t}}^{\alpha} \mathrm{q}\right)+\mathrm{dp}_{\beta}\left({ }_{\mathrm{t}} \mathrm{D}_{\mathrm{b}}^{\beta} \mathrm{q}\right)-\frac{\partial \mathcal{L}}{\partial \mathrm{q}} \mathrm{dq}-\frac{\partial \mathcal{L}}{\partial \mathrm{t}} \mathrm{dt}
$$

From the fractional Euler-Lagrange Eq. (54)

$$
\frac{\partial \mathcal{L}}{\partial \mathrm{q}}={ }_{-\mathrm{t}} \mathrm{D}_{\mathrm{b}}^{\alpha} \frac{\partial \mathcal{L}}{\partial_{{ }_{\mathrm{a}} \mathrm{D}_{\mathrm{t}}^{\alpha} \mathrm{q}}}-{ }_{\mathrm{a}} \mathrm{D}_{\mathrm{t}}^{\beta} \frac{\partial \mathcal{L}}{\partial_{\mathrm{a}} \mathrm{D}_{\mathrm{t}}^{\alpha} \mathrm{q}}
$$

We can get

$$
\begin{aligned}
\mathrm{d} \mathcal{H} & =\mathrm{dp}_{\alpha}\left({ }_{\mathrm{a}} \mathrm{D}_{\mathrm{t}}^{\alpha} \mathrm{q}\right)+\mathrm{dp}_{\beta}\left({ }_{\mathrm{t}} \mathrm{D}_{\mathrm{b}}^{\beta} \mathrm{q}\right) \\
& +\left({ }_{\mathrm{t}} \mathrm{D}_{\mathrm{b}}^{\alpha} \mathrm{p}_{\alpha}+{ }_{\mathrm{a}} \mathrm{D}_{\mathrm{t}}^{\beta} \mathrm{p}_{\beta}\right) \mathrm{dq}-\frac{\partial \mathcal{L}}{\partial \mathrm{t}} \mathrm{dt}
\end{aligned}
$$

which shows that $\mathcal{H}=\mathcal{H}\left(\mathrm{q}, \mathrm{p}_{\alpha}, \mathrm{p}_{\beta}, \mathrm{t}\right)$ is a function of the generalized coordinates, the generalized fractional momenta and $\mathrm{t}$. Taking the total differentiation

$$
\begin{aligned}
\mathrm{d} \mathcal{H}=\mathrm{d} \mathcal{H}\left(\mathrm{q}, \mathrm{p}_{\alpha}, \mathrm{p}_{\beta}, \mathrm{t}\right) & =\frac{\partial \mathcal{H}}{\partial \mathrm{q}} \mathrm{dq}+\frac{\partial \mathcal{H}}{\partial \mathrm{p}_{\alpha}} \mathrm{dp}_{\alpha} \\
& +\frac{\partial \mathcal{H}}{\partial \mathrm{p}_{\beta}} \mathrm{dp}_{\beta}+\frac{\partial \mathcal{H}}{\partial \mathrm{t}} \mathrm{dt}
\end{aligned}
$$

Comparing Eq. (54) and (55), the two total differentials of $\mathcal{H}$ we obtain:

$$
\left.\begin{array}{cc}
\frac{\partial \mathcal{H}}{\partial \mathrm{q}}=\left({ }_{\mathrm{t}} \mathrm{D}_{\mathrm{b}}^{\alpha} \mathrm{p}_{\alpha}+{ }_{\mathrm{a}} \mathrm{D}_{\mathrm{t}}^{\beta} \mathrm{p}_{\beta}\right) & \frac{\partial \mathcal{H}}{\partial \mathrm{p}_{\alpha}}=\left({ }_{\mathrm{a}} \mathrm{D}_{\mathrm{b}}^{\alpha} \mathrm{q}\right) \\
\frac{\partial \mathcal{H}}{\partial \mathrm{p}_{\beta}}=\left({ }_{\mathrm{t}} \mathrm{D}_{\mathrm{b}}^{\beta} \mathrm{q}\right) & \frac{\partial \mathcal{H}}{\partial \mathrm{t}}=\frac{\partial \mathcal{L}}{\partial \mathrm{t}}
\end{array}\right\}
$$

Transformation of $\left(\mathrm{q}, \mathrm{p}_{\alpha}, \mathrm{p}_{\beta}\right)$ into new variables

$\mathrm{Q}\left(\mathrm{q}, \mathrm{p}_{\alpha}, \mathrm{p}_{\beta}, \mathrm{t}\right), \mathrm{Q}_{\mathrm{a}}\left(\mathrm{q}, \mathrm{p}_{\alpha}, \mathrm{p}_{\beta}, \mathrm{t}\right), \mathrm{Q}_{\mathrm{b}}\left(\mathrm{q}, \mathrm{p}_{\alpha}, \mathrm{p}_{\beta}, \mathrm{t}\right)$

is canonical if there exists a new Hamiltonian $\mathcal{K}=\mathcal{K}\left(\mathrm{Q}, \mathrm{P}_{\alpha}, \mathrm{P}_{\beta}, \mathrm{t}\right)$ which satisfies modified Hamilton principle.

The motion of the system from time to time is such that the line integral called the action or the action integral $\mathcal{J}=\int_{\mathrm{t}_{1}=\mathrm{a}}^{\mathrm{t}_{2}=\mathrm{b}} \mathcal{L} \mathrm{dt}$ has a stationary
value for the actual path of the motion. i.e., the variation of the line integral is identically zero, (Goldstein, 2001)

$$
\begin{aligned}
& \mathcal{K}=\mathrm{P}_{\alpha}\left({ }_{\alpha} \mathrm{D}_{\mathrm{t}}^{\alpha} \mathrm{Q}\right)+\mathrm{P}_{\beta}\left({ }_{\mathrm{t}} \mathrm{D}_{\mathrm{b}}^{\beta} \mathrm{Q}\right)-\mathcal{L} \\
& \mathcal{L}=\mathrm{P}_{\alpha}\left({ }_{\alpha} \mathrm{D}_{\mathrm{t}}^{\alpha} \mathrm{Q}\right)+\mathrm{P}_{\beta}\left({ }_{\mathrm{t}} \mathrm{D}_{\mathrm{b}}^{\beta} \mathrm{Q}\right)-\mathcal{K}
\end{aligned}
$$

Thus the fractional Hamilton's principle can be written in the form:

$$
\left.\begin{array}{c}
\delta \int_{\mathrm{a}}^{\mathrm{b}}\left(\mathrm{P}_{\alpha}\left({ }_{\mathrm{a}} \mathrm{D}_{\mathrm{t}}^{\alpha} \mathrm{Q}\right)+\mathrm{P}_{\beta}\left({ }_{\mathrm{t}} \mathrm{D}_{\mathrm{b}}^{\beta} \mathrm{Q}\right)-\mathcal{K}\right) \mathrm{dt}=0 \\
\delta \int_{\mathrm{a}}^{\mathrm{b}}\left(\frac{\partial \mathcal{K}}{\partial \mathrm{Q}_{\alpha}}+\mathrm{P}_{\alpha} \frac{\partial \mathcal{K}}{\partial \mathrm{Q}_{\beta}} \mathrm{P}_{\beta}-\mathcal{K}\right) \mathrm{dt}=0
\end{array}\right\}
$$


As $\left(\mathrm{q}, \mathrm{p}_{\alpha}, \mathrm{p}_{\beta}\right)$ are canonically conjugate, they satisfy the fractional Hamilton's principle as

$$
\left.\begin{array}{c}
\delta \int_{\mathrm{a}}^{\mathrm{b}}\left(\mathrm{P}_{\alpha}\left({ }_{\mathrm{a}} \mathrm{D}_{\mathrm{t}}^{\alpha} \mathrm{q}\right)+\mathrm{P}_{\beta}\left({ }_{\mathrm{t}} \mathrm{D}_{\mathrm{b}}^{\beta} \mathrm{q}\right)-\mathcal{H}\right) \mathrm{dt}=0 \\
\delta \int_{\mathrm{a}}^{\mathrm{b}}\left(\frac{\partial \mathcal{K}}{\partial \mathrm{P}_{\alpha}} \mathrm{P}_{\alpha}+\frac{\partial \mathcal{H}}{\partial \mathrm{p}_{\beta}} \mathrm{P}_{\beta}-\mathcal{H}\right) \mathrm{dt}=0
\end{array}\right\}
$$

The simultaneous validity of Eq. (57) and (58) does not mean of course that the integrands in both expressions are equal. Since the general form of the Hamilton's principle has zero variation at the end points, both statements will be satisfied if the integrand differs by a total time derivative of an arbitrary function $\mathrm{W}$, hence

$$
\begin{aligned}
& \left(P_{\alpha}\left({ }_{a} D_{t}^{\alpha} Q\right) \quad P_{\beta}\left({ }_{t} D_{b}^{\beta} Q\right)\right) d t \\
& \quad-\left(P_{\alpha}\left({ }_{a} D_{t}^{\alpha} q\right)+P_{\beta}\left({ }_{t} D_{b}^{\beta} q\right)\right) d t \\
& +(\mathcal{K}-\mathcal{H}) d t=d W
\end{aligned}
$$

Since $\mathrm{W}$ is not varied at the end points, we get

$$
\delta \int_{a}^{b} \frac{d W}{d t}=\delta[W(b)-W(a)]=0
$$

The function $\mathrm{W}$, which completely determines the transformation, is called as a generating function. For mechanics involving fractional derivatives, we introduce variables $\left(\mathrm{u}_{\alpha}, \mathrm{u}_{\beta}, \mathrm{U}_{\alpha}, \mathrm{U}_{\beta}\right)$ satisfying:

$$
\left.\begin{array}{rlrl}
\frac{\mathrm{du} \alpha}{\mathrm{dt}}={ }_{\mathrm{a}} \mathrm{D}_{\mathrm{t}}^{\alpha} \mathrm{q} & \frac{\mathrm{du}_{\beta}}{\mathrm{dt}}={ }_{\mathrm{t}} \mathrm{D}_{\mathrm{b}}^{\beta} \mathrm{q} \\
\frac{\mathrm{dU} \mathrm{C}_{\alpha}}{\mathrm{dt}}={ }_{\mathrm{a}} \mathrm{D}_{\mathrm{t}}^{\alpha} \mathrm{Q} & \frac{\mathrm{dU}_{\beta}}{\mathrm{dt}}={ }_{\mathrm{t}} \mathrm{D}_{\mathrm{b}}^{\beta} \mathrm{Q}
\end{array}\right\}
$$

For integer-order derivatives, these new coordinates are the same as the usual canonical coordinates. However, while dealing with fractional derivatives, the coordinates $\left(\mathrm{u}_{\alpha}, \mathrm{u}_{\beta}, \mathrm{U}_{\alpha}, \mathrm{U}_{\beta}\right)$ will not be canonical. So to reserve the canonical form of the equations we try the following kinds of the generating function.

\section{Generating function of the first kind}

The generating function will be of the form $\mathrm{W}_{1}\left(\mathrm{u}_{\alpha}, \mathrm{u}_{\beta}, \mathrm{U}_{\alpha}, \mathrm{U}_{\beta}, \mathrm{t}\right)$. The total differential of $\mathrm{W}_{1}$ can be written as

$$
\begin{aligned}
\mathrm{dW}_{1}= & \frac{\partial \mathrm{W}_{1}}{\partial \mathrm{u}_{\alpha}} \mathrm{du}_{\alpha}+\frac{\partial \mathrm{W}_{1}}{\partial \mathrm{u}_{\beta}} \mathrm{du}_{\beta}+\frac{\partial \mathrm{W}_{1}}{\partial \mathrm{U}_{\alpha}} \mathrm{dU}_{\alpha} \\
& +\frac{\partial \mathrm{W}_{1}}{\partial \mathrm{U}_{\beta}} \mathrm{dU}_{\beta}+\frac{\partial \mathrm{W}_{1}}{\partial \mathrm{t}} \mathrm{dt} \\
\mathrm{dW}_{1}= & \left(\mathrm{P}_{\alpha}\left({ }_{\alpha} \mathrm{D}_{\mathrm{t}}^{\alpha} \mathrm{q}\right)+\mathrm{P}_{\beta}\left({ }_{\mathrm{t}} \mathrm{D}_{\mathrm{t}}^{\beta} \mathrm{q}\right)\right) \mathrm{dt} \\
& -\left(\mathrm{P}_{\alpha}\left({ }_{\alpha} \mathrm{D}_{\mathrm{t}}^{\alpha} \mathrm{Q}\right)+\mathrm{P}_{\beta}\left({ }_{\mathrm{t}} \mathrm{D}_{\mathrm{t}}^{\beta} \mathrm{Q}\right)\right) \mathrm{dt}+(\mathcal{K}-\mathcal{H}) \mathrm{dt} \\
\mathrm{dW}_{1}= & \mathrm{P}_{\alpha} \mathrm{du}_{\alpha}+\mathrm{p}_{\beta} \mathrm{du}_{\beta}-\mathrm{P}_{\alpha} \mathrm{dU}_{\alpha}-\mathrm{P}_{\beta} \mathrm{dU_{ \beta }}+(\mathcal{K}-\mathcal{H}) \mathrm{dt}
\end{aligned}
$$

Comparison between the two expressions Eqs. (60) and (61) yield

$$
\left.\begin{array}{ll}
\frac{\partial \mathrm{W}_{1}}{\partial \mathrm{u}_{\alpha}}=\mathrm{P}_{\alpha} & \frac{\partial \mathrm{W}_{1}}{\partial \mathrm{u}_{\beta}}=\mathrm{P}_{\beta} \\
\frac{\partial \mathrm{W}_{1}}{\partial \mathrm{U}_{\alpha}}=-\mathrm{P}_{\alpha} & \frac{\partial \mathrm{W}_{1}}{\partial \mathrm{u}_{\beta}}=-\mathrm{P}_{\beta} \\
& \frac{\partial \mathrm{W}_{1}}{\partial \mathrm{t}}=(\mathcal{K}-\mathcal{H})
\end{array}\right\}
$$




\section{Generating function of the second kind}

The generating function will be of the form $\mathrm{W}_{2}\left(\mathrm{u}_{\alpha}, \mathrm{u}_{\beta}, \mathrm{P}_{\alpha}, \mathrm{P}_{\beta}, \mathrm{t}\right)$. The total differential of $\mathrm{W}_{1}$ can be rewritten as:

$$
\begin{aligned}
& \mathrm{dW}_{1}=\frac{\partial \mathrm{W}_{1}}{\partial \mathrm{u}_{\alpha}} \mathrm{du}_{\alpha}+\frac{\partial \mathrm{W}_{1}}{\partial \mathrm{u}_{\beta}} \mathrm{du}_{\beta}+\frac{\partial \mathrm{W}_{1}}{\partial \mathrm{U}_{\alpha}} \mathrm{dU}_{\alpha}+\frac{\partial \mathrm{W}_{1}}{\partial \mathrm{U}_{\beta}} \mathrm{dU}_{\beta}+\frac{\partial \mathrm{W}_{1}}{\partial \mathrm{t}} \mathrm{dt} \\
& \mathrm{dW}_{1}=\mathrm{P}_{\alpha} \mathrm{du}_{\alpha}+\mathrm{P}_{\beta} \mathrm{du}_{\beta}+\mathrm{P}_{\alpha} \mathrm{dU}_{\alpha}-\mathrm{P}_{\beta} \mathrm{du}_{\beta}+(\mathcal{K}-\mathcal{H}) \mathrm{dt} \\
& \mathrm{dW}_{1}=\mathrm{P}_{\alpha} \mathrm{du}_{\alpha}+\mathrm{P}_{\beta} \mathrm{du}_{\beta}+\mathrm{P}_{\alpha} \mathrm{d} \mathrm{U}_{\alpha}-\left(\mathrm{U}_{\alpha} \mathrm{dP}_{\alpha}-\mathrm{U}_{\alpha} \mathrm{dP}_{\alpha}\right)-\mathrm{P}_{\beta} \mathrm{dU_{ \beta }} \\
& -\left(\mathrm{U}_{\beta} \mathrm{dP}_{\beta}-\mathrm{U}_{\beta} \mathrm{dP}_{\beta}\right)+(\mathcal{K}-\mathcal{H}) \mathrm{dt} \\
& \mathrm{dW}_{1}=\mathrm{P}_{\alpha} \mathrm{du}_{\alpha}+\mathrm{P}_{\beta} \mathrm{du}_{\beta}+\mathrm{P}_{\alpha} \mathrm{dU} \mathrm{U}_{\alpha}-\left(\mathrm{U}_{\alpha} \mathrm{dP}_{\alpha}-\mathrm{U}_{\alpha} \mathrm{dP}_{\alpha}\right)-\mathrm{P}_{\beta} \mathrm{dU_{ \beta }} \\
& -\left(\mathrm{U}_{\beta} \mathrm{dP}_{\beta}-\mathrm{U}_{\beta} \mathrm{dP}_{\beta}\right) \mathrm{U}_{\beta} \mathrm{dP}+(\mathcal{K}-\mathcal{H}) \mathrm{dt} \\
& \mathrm{dW}_{1}=\mathrm{P}_{\alpha} \mathrm{du}_{\alpha}+\mathrm{P}_{\beta} \mathrm{du}_{\beta}-\mathrm{d}\left(\mathrm{P}_{\alpha} \mathrm{U}_{\alpha}\right)+\mathrm{U}_{\alpha} \mathrm{dP} \mathrm{P}_{\alpha}-\mathrm{d}\left(\mathrm{P}_{\beta} \mathrm{U}_{\beta}\right)+\mathrm{U}_{\beta} \mathrm{dP}_{\beta} \\
& +(\mathcal{K}-\mathcal{H}) \mathrm{dt}
\end{aligned}
$$

We can rearrange the terms to yield an easy comparison of the expressions as

$$
\begin{aligned}
\mathrm{dW}_{1}=\mathrm{d}\left(\mathrm{P}_{\alpha} \mathrm{U}_{\alpha}\right)+\mathrm{d}\left(\mathrm{P}_{\beta} \mathrm{U}_{\beta}\right) & =\mathrm{P}_{\alpha} \mathrm{du} \mathrm{u}_{\alpha}+\mathrm{P}_{\beta} \mathrm{du} \mathrm{u}_{\beta}+\mathrm{U}_{\alpha} \mathrm{dP} \\
& +\mathrm{U}_{\beta} \mathrm{dP}_{\beta}+(\mathcal{K}-\mathcal{H}) \mathrm{dt} \\
\mathrm{dW}_{1}=\left(\mathrm{P}_{\alpha} \mathrm{U}_{\alpha}+\mathrm{P}_{\beta} \mathrm{U}_{\beta}\right) & =\mathrm{P}_{\alpha} \mathrm{du}_{\alpha}+\mathrm{P}_{\beta} \mathrm{du} \mathrm{u}_{\beta}+\mathrm{U}_{\alpha} \mathrm{dP} \\
+ & \mathrm{U}_{\beta} \mathrm{dP}_{\beta}+(\mathcal{K}-\mathcal{H}) \mathrm{dt}
\end{aligned}
$$

Now let:

$$
\begin{aligned}
\mathrm{dW}_{2}= & \mathrm{dW} \mathrm{W}_{1}+\mathrm{d}\left(\mathrm{P}_{\alpha} \mathrm{U}_{\alpha}\right)+\mathrm{d}\left(\mathrm{P}_{\beta} \mathrm{U}_{\beta}\right) \\
\mathrm{dW}_{2}= & \mathrm{P}_{\alpha} \mathrm{du}_{\alpha}+\mathrm{P}_{\beta} \mathrm{du}_{\beta}-\mathrm{P}_{\alpha} \mathrm{dU_{ \alpha }}-\mathrm{P}_{\beta} \mathrm{dU}_{\beta}+(\mathcal{K}-\mathcal{H}) \mathrm{dt} \\
& +\mathrm{d}\left(\mathrm{P}_{\alpha} \mathrm{U}_{\alpha}\right)+\mathrm{d}\left(\mathrm{P}_{\beta} \mathrm{U}_{\beta}\right) \\
\mathrm{dW}_{2}= & \mathrm{P}_{\alpha} \mathrm{du}_{\alpha}+\mathrm{P}_{\beta} \mathrm{du}_{\beta}-\mathrm{P}_{\alpha} \mathrm{dU_{ \alpha }}-\mathrm{P}_{\beta} \mathrm{dU}_{\beta}+(\mathcal{K}-\mathcal{H}) \mathrm{dt} \\
& +\left(\mathrm{P}_{\alpha} \mathrm{dU}_{\alpha}+\mathrm{U}_{\alpha} \mathrm{dP}_{\alpha}\right)+\mathrm{d}\left(\mathrm{P}_{\beta} \mathrm{U}_{\beta}+\mathrm{U}_{\beta} \mathrm{dP} \mathrm{P}_{\beta}\right) \\
\mathrm{dW}_{2}= & \mathrm{P}_{\alpha} \mathrm{du}_{\alpha}+\mathrm{P}_{\beta} \mathrm{du}_{\beta}+\mathrm{P}_{\alpha} \mathrm{dU_{ \alpha }}+\mathrm{P}_{\beta} \mathrm{dU}_{\beta}+(\mathcal{K}-\mathcal{H}) \mathrm{dt}
\end{aligned}
$$

Since $\mathrm{W}_{2}$ is a function of $\left(\mathrm{u}_{\alpha}, \mathrm{u}_{\beta}, \mathrm{P}_{\alpha}, \mathrm{P}_{\beta}, \mathrm{t}\right)$ we can write

$$
\begin{aligned}
\mathrm{dW}_{2} & =\frac{\partial \mathbf{W}_{2}}{\partial \mathbf{u}_{\alpha}} \mathbf{d u}_{\alpha}+\frac{\partial \mathbf{W}_{2}}{\partial \mathbf{u}_{\beta}} \mathbf{d u}_{\beta}+\frac{\partial \mathbf{W}_{2}}{\partial \mathbf{U}_{\alpha}} \mathbf{d P}_{\alpha} \\
& +\frac{\partial \mathbf{W}_{2}}{\partial \mathbf{U}_{\beta}} \mathbf{d P}_{\beta}+\frac{\partial \mathbf{W}_{2}}{\partial \mathrm{t}} \mathbf{d t}
\end{aligned}
$$

Comparison between the two expressions Eq. (63) and (64) yields

$$
\left.\begin{array}{ll}
\frac{\partial \mathbf{W}_{2}}{\partial \mathbf{u}_{\alpha}}=\mathbf{P}_{\alpha} & \frac{\partial \mathbf{W}_{2}}{\partial \mathbf{u}_{\beta}}=\mathbf{P}_{\beta} \\
\frac{\partial \mathbf{W}_{2}}{\partial \mathbf{U}_{\alpha}}=\mathbf{U}_{\alpha} & \frac{\partial \mathbf{W}_{2}}{\partial \mathbf{u}_{\beta}}=\mathbf{U}_{\beta} \\
& \frac{\partial \mathbf{W}_{2}}{\partial \mathbf{t}}=(\mathcal{K}-\mathcal{H})
\end{array}\right\}
$$




\section{Generating function of the third kind}

The generating function will be of the form $\mathrm{W}_{2}\left(\mathrm{u}_{\alpha}, \mathrm{u}_{\beta}, \mathrm{U}_{\alpha}, \mathrm{U}_{\beta}, \mathrm{t}\right)$. The total differential of $\mathrm{W}_{1}$ can be rewritten as:

$$
\begin{aligned}
\mathrm{dW}_{1} & =\frac{\partial \mathrm{W}_{1}}{\partial \mathrm{u}_{\alpha}} \mathrm{du}_{\alpha}+\frac{\partial \mathrm{W}_{1}}{\partial \mathrm{u}_{\beta}} \mathrm{du}_{\beta}+\frac{\partial \mathrm{W}_{1}}{\partial \mathrm{U}_{\alpha}} \mathrm{dU}_{\alpha}+\frac{\partial \mathrm{W}_{1}}{\partial \mathrm{U}_{\beta}} \mathrm{dU_{ \beta }}+\frac{\partial \mathrm{W}_{1}}{\partial \mathrm{t}} \mathrm{dt} \\
\mathrm{dW}_{1} & =\mathrm{P}_{\alpha} \mathrm{du}_{\alpha}+\mathrm{P}_{\beta} \mathrm{du}_{\beta}+\mathrm{P}_{\alpha} \mathrm{dU}_{\alpha}-\mathrm{P}_{\beta} \mathrm{du}_{\beta}+(\mathrm{K}-\mathrm{H}) \mathrm{dt} \\
\mathrm{dW}_{1} & =\mathrm{P}_{\alpha} \mathrm{du}_{\alpha}+\mathrm{P}_{\beta} \mathrm{du}_{\beta}+\mathrm{P}_{\alpha} \mathrm{dU_{ \alpha }}-\left(\mathrm{U}_{\alpha} \mathrm{dP}_{\alpha}-\mathrm{U}_{\alpha} \mathrm{dP}_{\alpha}\right)-\mathrm{P}_{\beta} \mathrm{dU}_{\beta} \\
& -\left(\mathrm{U}_{\beta} \mathrm{dP}_{\beta}-\mathrm{U}_{\beta} \mathrm{dP}_{\beta}\right)+(\mathrm{K}-\mathrm{H}) \mathrm{dt} \\
\mathrm{dW}_{1} & =\mathrm{P}_{\alpha} \mathrm{du}_{\alpha}+\mathrm{P}_{\beta} \mathrm{du}_{\beta}+\mathrm{P}_{\alpha} \mathrm{dU} \mathrm{U}_{\alpha}-\left(\mathrm{U}_{\alpha} \mathrm{dP} \mathrm{P}_{\alpha}-\mathrm{U}_{\alpha} \mathrm{dP} \mathrm{P}_{\alpha}\right)-\mathrm{P}_{\beta} \mathrm{dU}_{\beta} \\
& -\left(\mathrm{U}_{\beta} \mathrm{dP}_{\beta}-\mathrm{U}_{\beta} \mathrm{dP}_{\beta}\right) \mathrm{U}_{\beta} \mathrm{dP}+(\mathrm{K}-\mathrm{H}) \mathrm{dt} \\
\mathrm{dW} & =\mathrm{P}_{\alpha} \mathrm{du}_{\alpha}+\mathrm{P}_{\beta} \mathrm{du}_{\beta}-\mathrm{d}\left(\mathrm{P}_{\alpha} \mathrm{U}_{\alpha}\right)+\mathrm{U}_{\alpha} \mathrm{dP} \mathrm{P}_{\alpha}-\mathrm{d}\left(\mathrm{P}_{\beta} \mathrm{U}_{\beta}\right)+\mathrm{U}_{\beta} \mathrm{dP}_{\beta} \\
& +(\mathcal{K}-\mathcal{H}) \mathrm{dt}
\end{aligned}
$$

We can rearrange the terms to yield an easy comparison of the expressions as

$$
\begin{aligned}
\mathrm{dW}_{1}=\mathrm{d}\left(\mathrm{P}_{\alpha} \mathrm{U}_{\alpha}\right)-\mathrm{d}\left(\mathrm{P}_{\beta} \mathrm{U}_{\beta}\right) & =-\mathrm{P}_{\alpha} \mathrm{du}_{\alpha}-\mathrm{P}_{\beta} \mathrm{du}_{\beta}-\mathrm{U}_{\alpha} \mathrm{dP} \mathrm{P}_{\alpha} \\
-\mathrm{U}_{\beta} \mathrm{dP}_{\beta}-(\mathcal{K}-\mathcal{H}) \mathrm{dt} & \\
\mathrm{dW}_{1}=\left(\mathrm{P}_{\alpha} \mathrm{U}_{\alpha}-\mathrm{P}_{\beta} \mathrm{U}_{\beta}\right) & =-\mathrm{P}_{\alpha} \mathrm{du}_{\alpha}-\mathrm{P}_{\beta} \mathrm{du}_{\beta}-\mathrm{U}_{\alpha} \mathrm{dP} \mathrm{P}_{\alpha} \\
- & \mathrm{U}_{\beta} \mathrm{dP}_{\beta}-(\mathcal{K}-\mathcal{H}) \mathrm{dt}
\end{aligned}
$$

Now let:

$$
\begin{aligned}
\mathrm{dW}_{2}= & d \mathrm{~W}_{1}+\mathrm{d}\left(\mathrm{P}_{\alpha} \mathrm{U}_{\alpha}\right)+\mathrm{d}\left(\mathrm{P}_{\beta} \mathrm{U}_{\beta}\right) \\
\mathrm{dW}_{2}= & \mathrm{P}_{\alpha} \mathrm{du}_{\alpha}+\mathrm{P}_{\beta} \mathrm{du}_{\beta}-\mathrm{P}_{\alpha} \mathrm{dU_{ \alpha }}-\mathrm{P}_{\beta} \mathrm{dU_{ \beta }}+(\mathcal{K}-\mathcal{H}) \mathrm{dt} \\
& +\mathrm{d}\left(\mathrm{P}_{\alpha} \mathrm{U}_{\alpha}\right)+\mathrm{d}\left(\mathrm{P}_{\beta} \mathrm{U}_{\beta}\right) \\
\mathrm{dW}_{2}= & \mathrm{P}_{\alpha} \mathrm{du}_{\alpha}+\mathrm{P}_{\beta} \mathrm{du}_{\beta}-\mathrm{P}_{\alpha} \mathrm{dU_{ \alpha }}-\mathrm{P}_{\beta} \mathrm{dU}_{\beta}+(\mathcal{K}-\mathcal{H}) \mathrm{dt} \\
& +\left(\mathrm{P}_{\alpha} \mathrm{dU}_{\alpha}+\mathrm{U}_{\alpha} \mathrm{dP} \mathrm{P}_{\alpha}\right)+\mathrm{d}\left(\mathrm{P}_{\beta} \mathrm{U}_{\beta}+\mathrm{U}_{\beta} \mathrm{dP}_{\beta}\right)
\end{aligned}
$$

$$
\mathrm{dW}_{2}=\mathrm{P}_{\alpha} \mathrm{du}_{\alpha}+\mathrm{P}_{\beta} \mathrm{du}_{\beta}+\mathrm{P}_{\alpha} \mathrm{dU}_{\alpha}+\mathrm{P}_{\beta} \mathrm{dU}_{\beta}+(\mathcal{K}-\mathcal{H}) \mathrm{dt}
$$

Since $\mathrm{W}_{3}$ is a function of $\left(\mathrm{P}_{\mathrm{a}}, \mathrm{P}_{\beta}, \mathrm{U}_{\alpha}, \mathrm{U}_{\beta}, \mathrm{t}\right)$ we can write

$$
\begin{aligned}
\mathrm{dW}_{3} & =\frac{\partial \mathbf{W}_{3}}{\partial \mathbf{u}_{\alpha}} \mathbf{d u}_{\alpha}+\frac{\partial \mathbf{W}_{3}}{\partial \mathbf{u}_{\beta}} \mathbf{d u}_{\beta}+\frac{\partial \mathbf{W}_{3}}{\partial \mathbf{U}_{\alpha}} \mathbf{d P}_{\alpha} \\
& +\frac{\partial \mathbf{W}_{3}}{\partial \mathbf{U}_{\beta}} \mathrm{dP}_{\beta}+\frac{\partial \mathbf{W}_{3}}{\partial \mathrm{t}} \mathrm{dt}
\end{aligned}
$$

Comparison between the two expressions Eq. (66) and (67) yields:

$$
\left.\begin{array}{cc}
\frac{\partial \mathbf{W}_{3}}{\partial \mathbf{u}_{\alpha}}=-\mathbf{u}_{\alpha} & \frac{\partial \mathbf{W}_{3}}{\partial \mathbf{u}_{\beta}}=-\mathbf{u}_{\beta} \\
\frac{\partial \mathbf{W}_{3}}{\partial \mathbf{U}_{\alpha}}=-\mathbf{p}_{\alpha} & \frac{\partial \mathbf{W}_{3}}{\partial \mathbf{u}_{\beta}}=-\mathbf{p}_{\beta} \\
\frac{\partial \mathbf{W}_{3}}{\partial \mathrm{t}}=(\mathcal{K}-\mathcal{H})
\end{array}\right\}
$$




\section{Generating function of the fourth kind}

The generating function will be of the form $\mathrm{W}_{4}\left(\mathrm{p}_{\alpha}, \mathrm{p}_{\beta}, \mathrm{P}_{\alpha}, \mathrm{P}_{\beta}, \mathrm{t}\right)$. The total differential of $\mathrm{W}_{1}$ can be rewritten as:

$\mathrm{dW}_{1}=\frac{\partial \mathrm{W}_{1}}{\partial \mathrm{u}_{\alpha}} \mathrm{du}_{\alpha}+\frac{\partial \mathrm{W}_{1}}{\partial \mathrm{u}_{\beta}} \mathrm{du}_{\beta}+\frac{\partial \mathrm{W}_{1}}{\partial \mathrm{U}_{\alpha}} \mathrm{dU}_{\alpha}+\frac{\partial \mathrm{W}_{1}}{\partial \mathrm{U}_{\beta}} \mathrm{dU}_{\beta}+\frac{\partial \mathrm{W}_{1}}{\partial \mathrm{t}} \mathrm{dt}$

$\mathrm{dW}_{1}=\mathrm{P}_{\alpha} \mathrm{du}_{\alpha}+\mathrm{P}_{\beta} \mathrm{du}_{\beta}+\mathrm{P}_{\alpha} \mathrm{dU}_{\alpha}-\mathrm{P}_{\beta} \mathrm{du}_{\beta}+(\mathcal{K}-\mathcal{H}) \mathrm{dt}$

$\mathrm{dW}_{1}=\mathrm{P}_{\alpha} \mathrm{du}_{\alpha}+\mathrm{P}_{\beta} \mathrm{du}_{\beta}+\mathrm{P}_{\alpha} \mathrm{dU_{ \alpha }}-\left(\mathrm{U}_{\alpha} \mathrm{dP}_{\alpha}-\mathrm{U}_{\alpha} \mathrm{dP}_{\alpha}\right)-\mathrm{P}_{\beta} \mathrm{dU}_{\beta}$

$-\left(\mathrm{U}_{\beta} \mathrm{dP}_{\beta}-\mathrm{U}_{\beta} \mathrm{dP}_{\beta}\right)+(\mathcal{K}-\mathcal{H}) \mathrm{dt}$

$\mathrm{dW}_{1}=\mathrm{P}_{\alpha} \mathrm{du}_{\alpha}+\mathrm{P}_{\beta} \mathrm{du}_{\beta}+\mathrm{P}_{\alpha} \mathrm{dU}_{\alpha}-\left(\mathrm{U}_{\alpha} \mathrm{dP}_{\alpha}-\mathrm{U}_{\alpha} \mathrm{dP}_{\alpha}\right)-\mathrm{P}_{\beta} \mathrm{dU}_{\beta}$

$-\left(\mathrm{U}_{\beta} \mathrm{dP}_{\beta}-\mathrm{U}_{\beta} \mathrm{dP}_{\beta}\right) \mathrm{U}_{\beta} \mathrm{dP}+(\mathcal{K}-\mathcal{H}) \mathrm{dt}$

$\mathrm{dW}_{1}=\mathrm{P}_{\alpha} \mathrm{du}_{\alpha}+\mathrm{P}_{\beta} \mathrm{du}_{\beta}-\mathrm{d}\left(\mathrm{P}_{\alpha} \mathrm{U}_{\alpha}\right)+\mathrm{U}_{\alpha} \mathrm{dP}-\mathrm{d}\left(\mathrm{P}_{\beta} \mathrm{U}_{\beta}\right)+\mathrm{U}_{\beta} \mathrm{dP}$

$+(\mathcal{K}-\mathcal{H}) \mathrm{dt}$

We can rearrange the terms to yield an easy comparison of the expressions as

$$
\begin{aligned}
\mathrm{dW}_{1}=\mathrm{d}\left(\mathrm{P}_{\alpha} \mathrm{u}_{\alpha}\right)-\mathrm{d}\left(\mathrm{p}_{\beta} \mathrm{u}_{\beta}\right)= & -\mathrm{p}_{\alpha} \mathrm{du}_{\alpha}-\mathrm{p}_{\beta} \mathrm{du}_{\beta}-\mathrm{u}_{\alpha} \mathrm{dp} \mathrm{p}_{\alpha} \\
& -\mathrm{u}_{\beta} \mathrm{dp_{ \beta }}-(\mathcal{K}-\mathcal{H}) \mathrm{dt} \\
\mathrm{dW}_{1}=\left(\mathrm{P}_{\alpha} \mathrm{u}_{\alpha}-\mathrm{p}_{\beta} \mathrm{u}_{\beta}+\mathrm{P}_{\alpha} \mathrm{u}_{\alpha}-\mathrm{P}_{\beta} \mathrm{u}_{\beta}\right)-\mathrm{P}_{\alpha} \mathrm{du} \mathrm{u}_{\alpha} & -\mathrm{p}_{\beta} \mathrm{du} \mathrm{u}_{\beta}-(\mathcal{K}-\mathcal{H}) \mathrm{dt}
\end{aligned}
$$

Now let

$$
\begin{aligned}
\mathrm{dW}_{4}= & d W_{1}+\mathrm{d}\left(\mathrm{P}_{\alpha} \mathrm{U}_{\alpha}\right)+\mathrm{d}\left(\mathrm{P}_{\beta} \mathrm{U}_{\beta}\right) \\
\mathrm{dW}_{4}= & \mathrm{P}_{\alpha} \mathrm{du}_{\alpha}+\mathrm{P}_{\beta} \mathrm{du}_{\beta}-\mathrm{P}_{\alpha} \mathrm{dU}_{\alpha}-\mathrm{P}_{\beta} \mathrm{dU}_{\beta}+(\mathcal{K}-\mathcal{H}) \mathrm{dt} \\
& +\mathrm{d}\left(\mathrm{P}_{\alpha} \mathrm{U}_{\alpha}\right)+\mathrm{d}\left(\mathrm{P}_{\beta} \mathrm{U}_{\beta}\right) \\
\mathrm{dW}_{4}= & \mathrm{P}_{\alpha} \mathrm{du}_{\alpha}+\mathrm{P}_{\beta} \mathrm{du}_{\beta}-\mathrm{P}_{\alpha} \mathrm{dU}_{\alpha}-\mathrm{P}_{\beta} \mathrm{dU}_{\beta}+(\mathcal{K}-\mathcal{H}) \mathrm{dt} \\
& +\left(\mathrm{P}_{\alpha} \mathrm{dU}_{\alpha}+\mathrm{U}_{\alpha} \mathrm{dP} \mathrm{P}_{\alpha}\right)+\mathrm{d}\left(\mathrm{P}_{\beta} \mathrm{U}_{\beta}+\mathrm{U}_{\beta} \mathrm{dP} \mathrm{P}_{\beta}\right) \\
& \mathrm{dW}_{4}=\mathrm{P}_{\alpha} \mathrm{du}_{\alpha}+\mathrm{P}_{\beta} \mathrm{du}_{\beta}+\mathrm{P}_{\alpha} \mathrm{dU_{ \alpha }}+\mathrm{P}_{\beta} \mathrm{dU}_{\beta}+(\mathcal{K}-\mathcal{H}) \mathrm{dt}
\end{aligned}
$$

Since $\mathrm{W}_{4}$ is a function of $\left(\mathrm{p}_{\alpha}, \mathrm{p}_{\beta}, \mathrm{P}_{\alpha}, \mathrm{P}_{\beta}, \mathrm{t}\right)$ we can write

$$
\begin{aligned}
\mathbf{d W}_{4} & =\frac{\partial \mathbf{W}_{4}}{\partial \mathbf{u}_{\alpha}} \mathbf{d} \mathbf{p}_{\alpha}+\frac{\partial \mathbf{W}_{4}}{\partial \mathbf{u}_{\beta}} \mathbf{d p}_{\beta}+\frac{\partial \mathbf{W}_{4}}{\partial \mathbf{U}_{\alpha}} \mathbf{d P}_{\alpha} \\
& +\frac{\partial \mathbf{W}_{4}}{\partial \mathbf{U}_{\beta}} \mathbf{d P}_{\beta}+\frac{\partial \mathbf{W}_{4}}{\partial \mathbf{t}} \mathbf{d t}
\end{aligned}
$$

Comparison between the two expressions yields

$$
\left.\begin{array}{cc}
\frac{\partial \mathbf{W}_{4}}{\partial \mathbf{u}_{\alpha}}=-\mathbf{u}_{\alpha} & \frac{\partial \mathbf{W}_{4}}{\partial \mathbf{u}_{\beta}}=-\mathbf{u}_{\beta} \\
\frac{\partial \mathbf{W}_{4}}{\partial \mathbf{U}_{\alpha}}=-\mathbf{U}_{\alpha} & \frac{\partial \mathbf{W}_{4}}{\partial \mathbf{u}_{\beta}}=-\mathbf{U}_{\beta} \\
\frac{\partial \mathbf{W}_{4}}{\partial \mathbf{t}}=(\mathcal{K}-\mathcal{H})
\end{array}\right\}
$$

It is observed from all transformation that the partial differentiation of any generating function with respect to time is the difference between the 
new and the old Hamiltonian functions $\frac{\partial \mathrm{W}}{\partial \mathrm{t}}=(\mathcal{K}-\mathcal{H})$. If the generating function does not depend explicitly on time then we can conclude that ( $\mathcal{K}-\mathcal{H})$.

\section{Fractional Poisson bracket}

Based on the concepts of FC, Hamiltonian mechanics can be reformulated in terms of the generalized Poisson brackets (fractional version). If functions $\mathrm{F}\left(\mathrm{q}, \mathrm{p}_{\alpha}, \mathrm{p}_{\beta}, \mathrm{t}\right)$ and $\mathrm{W}\left(\mathrm{q}, \mathrm{p}_{\alpha}, \mathrm{p}_{\beta}, \mathrm{t}\right)$ depend on the generalized coordinate, generalized fractional momenta and time, we can generalize Poisson bracket of $\mathrm{F}$ and $\mathrm{W}$, denoted as $(\mathrm{F}, \mathrm{W})$ so as to include the fractional derivatives as:

$$
(\mathrm{F}, \mathrm{W})=\frac{\partial \mathrm{F}}{\partial \mathrm{q}}\left(\frac{\partial \mathrm{W}}{\partial \mathrm{p}_{\alpha}}+\frac{\partial \mathrm{W}}{\partial \mathrm{p}_{\beta}}\right)-\frac{\partial \mathrm{W}}{\partial \mathrm{q}}\left(\frac{\partial \mathrm{F}}{\partial \mathrm{p}_{\alpha}}+\frac{\partial \mathrm{F}}{\partial \mathrm{p}_{\beta}}\right)
$$

All the properties of the ordinary Poisson bracket are holding true for the fractional Poisson brackets; e.g.

$$
\begin{aligned}
& (\mathrm{F}, \mathrm{W})=-(\mathrm{F}, \mathrm{W}), \quad\left(\mathrm{F}_{1}+\mathrm{F}_{2}, \mathrm{~W}\right)=\left(\mathrm{F}_{1}, \mathrm{~W}\right)+\left(\mathrm{F}_{2}, \mathrm{~W}\right) \\
& (\mathrm{F}, \mathrm{q})=-\frac{\partial \mathrm{W}}{\partial \mathrm{q}}\left(\frac{\partial \mathrm{F}}{\partial \mathrm{p}_{\alpha}}+\frac{\partial \mathrm{F}}{\partial \mathrm{p}_{\beta}}\right), \quad\left(\mathrm{F}, \mathrm{P}_{\alpha}\right)=\left(\mathrm{F}, \mathrm{P}_{\beta}\right)=\frac{\partial \mathrm{F}}{\partial \mathrm{q}}
\end{aligned}
$$

and

$$
\begin{aligned}
& \left(\mathrm{q}, \mathrm{p}_{\alpha}\right)=\left(\mathrm{p}_{\alpha}, \mathrm{p}_{\beta}\right)=1 \\
& (\mathrm{q}, \mathrm{q})=\left(\mathrm{p}_{\alpha}, \mathrm{p}_{\alpha}\right)=\left(\mathrm{p}_{\beta}, \mathrm{p}_{\beta}\right)=\left(\mathrm{p}_{\alpha}, \mathrm{p}_{\beta}\right)=0 \\
& \left(\mathrm{~F}_{1},\left(\mathrm{~F}_{2}, \mathrm{~F}_{3}\right)\right)+\left(\mathrm{F}_{2},\left(\mathrm{~F}_{2}, \mathrm{~F}_{1}\right)\right)+\left(\mathrm{F}_{3},\left(\mathrm{~F}_{2}, \mathrm{~F}_{1}\right)\right)=0
\end{aligned}
$$

\section{Fractional Hamilton-Jacobi equation}

The Hamilton-Jacobi (H-J) equation results from a canonical transformation for which the new variables are constant. For integer-order derivatives, such a transformation will follow automatically if the new Hamiltonian $\mathcal{K}$ is identically zero, since from the equations of motion we then have

$$
\mathbf{Q}=\frac{\partial \mathcal{H}}{\partial \mathbf{P}}=\mathbf{O} \quad \mathbf{P}=-\frac{\partial \mathcal{H}}{\partial \mathbf{Q}}
$$

The method aims to find a suitable generating function that must satisfy the partial differential Eq. (73)

$$
\frac{\partial \mathbf{W}}{\partial \mathbf{t}}+\mathcal{H}(\mathbf{q}, \mathbf{p}, \mathbf{t})=\mathbf{O}
$$

For the fractional derivatives, we can derive a similar relationship by putting:

$$
\left.\begin{array}{l}
\frac{\partial \mathrm{W}}{\partial \mathrm{t}}+\mathcal{H}(\mathrm{q}, \mathrm{p}, \mathrm{t})=\mathbf{0} \\
\frac{\partial \mathrm{W}}{\partial \mathrm{t}}+\mathcal{H}\left(\mathrm{q},{ }_{\alpha} \mathrm{D}_{\mathrm{t}}^{\alpha} \mathrm{q},{ }_{\mathrm{t}} \mathrm{D}_{\mathrm{b}}^{\beta} \mathrm{q}, \mathrm{t}\right)=\mathbf{0} \\
\frac{\partial \mathrm{W}}{\partial \mathrm{t}}+\mathcal{H}\left(\frac{\partial \mathrm{W}}{\partial \mathbf{u}_{\alpha}}, \frac{\partial \mathrm{W}}{\partial \mathbf{u}_{\beta}}, \mathrm{t}\right)=0
\end{array}\right\}
$$

\section{Conclusion}

We outlined the fundamental properties of fractional derivative and examined the behavior of some elementary functions under the effect of the fractional differintegral operator. We obtained a fractional form of the Euler Lagrange equation using the Riemann-Lowville differ integral operator. Also we formulated the fractional Hamilton's canonical equations. We derived different canonical transformations with different generating functions. Finally we introduced the fractional Poisson bracket. 


\section{Acknowledgments}

The author is deeply indebted to the team work at the deanship of the scientific research, Taibah University for their valuable help and critical guidance and for facilitating many administrative procedures. This research work was financed supported by Grant no. 1767/1433 from the deanship of the scientific research at Taibah university, Al-Madinah Al-Munawwarah, Saudi Arabia.

\section{References}

1 Baleanu D (2008) New applications of fractional variational principles. Reports Math. Phys. 61, 199-206.

2 Agrawal OP (2002) Formulation of Euler-Lagrange equations for fractional variational problems. J Math. Anal. Appl. 272, 368379.

3• Agrawal OP (2006) J. Phys. A: Math. Gen. 39, 10375

4• Agrawal OP (2007) J. Phys. A: Math. Theor. 40, 5469

5. Baleanu D and Muslih S (2005b) Formulation of Hamiltonian equations for fractional variational problems. Czech. J. Phys., 55: 633-642.

6• Baleanu DI and Muslih S (2005a) Lagrangian formulation of classical fields within Riemann-Lowville fractional derivatives. Phys. Scripta. 72, 119-121.

7• Eqab MR and Ababneh BS (2008) Hamilton-Jacobi fractional mechanics. J. Math. Anal. Appl. 344, 799-805.

8• Goldstein H (2001) Classical mechanics. 3rd Edn. Addison-Wesley Pub. Co.

9• Kilbas AA, Srivastava HM and Trujillo JJ (2006) Theory and applications of fractional differential equations. Elsevier, Amsterdam.

10 Magin RL (2006) Fractional calculus in bioengineering, Begell House Publisher, Inc., Connecticut.

11 Miller KS and Ross B (1993) An Introduction to the Fractional Integrals and Derivatives-Theory and Applications. John Wiley and Sons.

12- Oldham KB and Spanier J (1974) The fractional calculus, Academic Press, New York.

13- Podlubny I (1999) Fractional differential equations mathematics in science and engineering, V198. Academic Press, San Diego.

14 Riemann B (1876) Versuch einer allgemeinen Auffassung der Integration und Differentiation. Gesammelte Werke, pp: 62.

15• Riewe F (1996) Nonconservative lagrangian and hamiltonian mechanics. Phys. Rev. E53, 1890-1899.

16• Riewe F (1997) Mechanics with fractional derivatives. Phys. Rev. E55, 3581-3592.

17. Samko SG, Kilbas AA and Marichev OI (1993) Fractional integrals and derivatives-theory and applications, Gordon and Breach. Longhorne, PA. 